\title{
The Global Ozone Monitoring Experiment: review of in-flight performance and new reprocessed 1995-2011 level 1 product
}

\author{
Melanie Coldewey-Egbers ${ }^{1}$, Sander Slijkhuis ${ }^{1}$, Bernd Aberle ${ }^{1}$, Diego Loyola ${ }^{1}$, and Angelika Dehn ${ }^{2}$ \\ ${ }^{1}$ German Aerospace Center (DLR), Remote Sensing Technology Institute, Oberpfaffenhofen, Germany \\ ${ }^{2}$ European Space Agency (ESA), ESRIN, Frascati, Italy \\ Correspondence: Melanie Coldewey-Egbers (melanie.coldewey-egbers@ dlr.de)
}

Received: 16 April 2018 - Discussion started: 18 May 2018

Revised: 20 August 2018 - Accepted: 29 August 2018 - Published: 18 September 2018

\begin{abstract}
The Global Ozone Monitoring Experiment (GOME) on-board the second European Remote Sensing satellite provided measurements of atmospheric constituents such as ozone and other trace gases for the 16-year period from 1995 to 2011. In this paper we present a detailed analysis of the long-term performance of the sensor and introduce the new homogenised and fully calibrated level 1 product that has been generated using the recently developed GOME Data Processor level-0-to-1b (GDP-L1) Version 5.1. By means of the various in-flight calibration parameters, we monitor the behaviour and stability of the instrument during the entire mission. Severe degradation of the optical components has led to a significant decrease in intensity, in particular in channels 1 and 2, which cover the spectral ranges of 240-316 and 311-405 nm, respectively. Thus, a soft correction based on using the Sun as a stable calibration source is applied. Revision and optimisation of other calibration algorithms such as the wavelength assignment, polarisation correction, and dark current correction resulted in an improved and homogeneous level 1 product that can be regarded as the European satellite reference data for successor atmospheric composition sensors and that provides an excellent prerequisite for further exploitation of GOME measurements.
\end{abstract}

\section{Introduction}

The Global Ozone Monitoring Experiment (GOME) was launched on 21 April 1995 by the European Space Agency (ESA) on-board the second European Remote Sensing satellite (ERS-2). It was the first European UVVIS-NIR (ultraviolet-visible-near-infrared) spectrometer in space dedicated to observing atmospheric trace constituents such as ozone, nitrogen dioxide, sulfur dioxide, formaldehyde, bromine, and water vapour as well as cloud and aerosol parameters on a global scale (Burrows et al., 1999). The sensor operated for more than 16 years, which is a world record for this kind of instrument, until the retirement of the ERS-2 platform in early July 2011. GOME is the predecessor of a series of similar follow-up instruments like SCIAMACHY (Scanning Imaging Absorption Spectrometer for Atmospheric Chartography, 2002-2012, Bovensmann et al., 1999) on-board Envisat, OMI (Ozone Monitoring Instrument, launched in 2004 on-board Aura, Levelt et al., 2006), GOME-2 (Munro et al., 2016) on-board the MetOp satellite series, or the Copernicus Sentinel missions TROPOMI onboard Sentinel-5 Precursor, Sentinel-4, and Sentinel-5, and marks the beginning of European operational, global, longterm monitoring of climate-relevant atmospheric parameters.

The existing atmospheric data archive of GOME is of very high value and may be considered (in conjunction with SCIAMACHY) as the basis for a future reference data set for successor sensors. The status of scientific results of the miscellaneous GOME level 2 data products is presented in numerous publications (e.g., Balis et al., 2007; de Smedt et al., 2008; Loyola et al., 2010; van Roozendael et al., 2012; Lerot et al., 2014). Furthermore, GOME data form a substantial part of recently developed long-term climate data records, for example the GOME-type Total Ozone Essential Climate Variable and the harmonised tropical tropospheric ozone data records generated within the framework of the ESA's outstanding Climate Change Initiative (Coldewey-Egbers et al., 2015; Heue et al., 2016). 
In 2012 at ESA's Atmospheric Science Conference, as a result of the discussion rounds, the scientific user community formulated a set of recommendations (ATMOS, 2012) also addressing the preservation and further exploitation of the 16 years of GOME measurements. These recommendations have led to ESA's GOME-Evolution project that started in April 2014. Among other topics, the objective of this activity is to provide the Earth Observation (EO) user community with improved and consolidated GOME level 1 products, in an easily accessible common data format, based on updated GOME calibration algorithms and improved in-flight calibration characterisation for the complete mission. Homogenisation of the current GOME level 1 products has become necessary because so far they were generated using different processor versions and, thus, were not fully consistent during the complete mission.

Furthermore, a detailed investigation of the long-term performance of the GOME instrument for the entire mission period was carried out in the framework of GOME-Evolution. The results will be presented in this paper. This part of the study is an extension of the work by Coldewey-Egbers et al. (2008), who introduced a first overview of the long-term behaviour for the 11-year time span from 1995 to 2006. Special emphasis is put on the analysis of the Sun mean reference (SMR) spectra in order to monitor and correct for the gradual degradation of the instrument's optical properties. ColdeweyEgbers et al. (2008) have shown that the degradation is particularly severe in the UV channels $1(\sim 70 \%-90 \%)$ and 2 ( $\sim 35 \%-65 \%$ ), covering the spectral range of $240-316$ and 311-405 nm, respectively. Similar changes are observed for SCIAMACHY and GOME-2 (Noël et al., 2007; Bramstedt et al., 2009; Munro et al., 2016), whereas they are considerably smaller for OMI (Schenkeveld et al., 2017).

The various in-flight calibration parameters are a good means to monitor the long-term stability of the sensor and its measurements. Instrument stability is one of the most important prerequisites to meet the challenge of measuring very small changes in atmospheric parameters associated with long-term climate change from space. For example, satellite sensors are required to detect ozone trends of the order of $1 \%$ decade $^{-1}$ (GCOS, 2011). Amongst other things, in our study particular attention was paid to the analysis of the long-term performance and stability of the spectral calibration, since errors in wavelength assignment may have a significant impact on the Earth albedo and trace gas retrievals (Voors et al., 2006; van Geffen et al., 2015; Pan et al., 2017).

In addition to the new GOME level 1 product and the revised in-flight calibration data set, a "Climate" total column water vapour product (Beirle et al., 2018) has been developed within the ESA GOME-Evolution project. It is based on homogenised GOME, SCIAMACHY, and GOME-2 observations and provides a consistent time series that is dedicated to the study of the temporal evolution of water vapour over the past 2 decades on a global scale. Another part of the project was the creation of a web gallery (Weber et al.,
2018) featuring the GOME/ERS-2 mission and related scientific achievements.

The paper is organised as follows: In Sect. 2 we provide an overview of the GOME instrument design and brief descriptions of the level-0-to-1 processing chain and the new level 1 product. Section 3 contains a summary of the calibration algorithms using results of the on-ground instrument characterisation. An analysis of the Sun mean reference spectra and the description of the degradation correction algorithm is presented in Sect. 4.1, followed by the investigation of the polarisation measurement device (PMD) data (Sect. 4.2). In Sect. 4.3 we show results of the reflectance degradation analysis. Section 5 contains the detailed results of the long-term analysis of the most important GOME in-flight calibration parameters needed for, for example, the spectral calibration or the dark current correction. Summary and concluding remarks are finally given in Sect. 6.

\section{GOME/ERS-2}

\subsection{Instrument and platform characteristics}

GOME is a nadir-viewing, across-track scanning spectrometer that covers the ultraviolet, visible, and near-infrared wavelength range from 240 to $790 \mathrm{~nm}$ with moderate spectral resolution of 0.2 to $0.4 \mathrm{~nm}$. It measures the solar radiation reflected and scattered by the Earth's atmosphere and surface as well as the solar irradiance. Its primary objective is the determination of the amounts and distributions of atmospheric trace constituents, such as ozone, nitrogen dioxide, sulfur dioxide, formaldehyde, or bromine oxide as well as cloud and aerosol parameters (Burrows et al., 1999). In normal viewing mode, there are three forward scans (footprint size of $320 \times 40 \mathrm{~km}^{2}$ each - across-track $\times$ along-track) followed by a backscan with $1.5 \mathrm{~s}$ integration time each. The maximum swath width is $960 \mathrm{~km}$, and global coverage is achieved at the Equator within 3 days.

GOME is a double monochromator, which has as dispersing elements a pre-disperser prism, combined with a holographic grating in each of the four optical channels. The earthshine radiance and solar irradiance spectra are recorded with four linear Si-diode arrays with 1024 spectral elements each. These detectors are cooled to $235 \mathrm{~K}$ by means of Peltier coolers to reduce dark currents and to improve the signal-tonoise ratio. The four channels cover the wavelength regions of 240-316 nm (channel 1), 311-405 nm (channel 2), 405$611 \mathrm{~nm}$ (channel 3), and 595-793 nm (channel 4). Channels 1 and 2 are further electronically divided into two bands ("a" and "b") covering the short-wavelength and long-wavelength parts of the channels, respectively. In addition there are four stray light bands: two shortwave of band 1a, one longwave of band $1 \mathrm{~b}$, and one shortwave of band 2a. Part of the light is branched out at the pre-disperser prism and recorded with three fast broadband silicon photo-diodes, the PMDs, whose 
spectral ranges cover approximately the optical channels 2 (300-400 nm), $3(400-580 \mathrm{~nm})$, and $4(580-750 \mathrm{~nm})$, respectively. They measure the amount of light polarised parallel to the instrument slit, which is perpendicular to the plane of incidence of the scan mirror. The PMDs are non-integrating detectors which are continuously sampled, albeit over an RC circuit which has an averaging effect over the sampling time. The corresponding sampling time of the PMD measurements is $93.75 \mathrm{~ms}$; i.e., 16 PMD measurements are available for one detector channel measurement at the default integration time of $1.5 \mathrm{~s}$.

In addition to solar and Earth nadir viewing, the various pointing geometries of the GOME scan mirror permit polar viewing (viewing angle of $45^{\circ}$ ) and lunar observations (viewing angle of about $80^{\circ}$ ) at selected times during a year. A calibration unit adjacent to the spectrometer part consists of the Sun view port and a compartment housing a platinumneon-chromium $(\mathrm{Pt} / \mathrm{Ne} / \mathrm{Cr}$ ) hollow cathode discharge lamp. The solar radiation is attenuated by a $20 \%$ transmission mesh and directed via a diffuser plate (wet-sanded aluminium plate with chromium-aluminium coating) onto the entrance slit of the spectrometer. The calibration unit becomes optically coupled to the spectrometer by appropriate positioning of the scan mirror.

A detailed overview of the GOME instrument, its operation, and its scientific methods can be found in the GOME Users Manual (GOME Users Manual, 1995) and in Burrows et al. (1999). For understanding the algorithm principles described in the following sections, a simple functional diagram of the GOME instrument is shown in Fig. 1. The most important instrument components relevant to the level-0-to-1 calibration are as follows:

- the scan mirror whose position is linked to the observation mode, e.g., nadir or pole scanning, static or moon view, and the calibration mode (the latter comprises solar measurements, dark signal measurements, and spectral lamp measurements);

- the calibration unit that hosts the spectral calibration lamp and the Sun diffuser;

- the slit that limits the instantaneous field of view to $2.9^{\circ} \times 0.142^{\circ}$ or $40 \times 2 \mathrm{~km}^{2}$ on the ground (the slit function, i.e., the instrument spectral response to monochromatic input, is a convolution of projected slit width, pixel response, and optical abberations);

- the quartz pre-disperser prism where part of the light is branched out and directed towards the PMD unit (see below);

- the channel separator prism in the intermediate focus that acts as a spatial filter to separate the wavelengths for channel 1, for channel 2, and for channels 3 and 4, respectively (this separation serves to reduce stray light on the UV detectors, i.e., channels 1 and 2);
- the dichroic filter that separates the wavelengths of channel 3 from those of channel 4 (in the spectral range from 590 to $610 \mathrm{~nm}$ the filter changes from reflection to transmission);

- the channel optics that consists for each channel of 4 quartz lenses mounted in one barrel;

- four red LEDs which illuminate the detectors directly and which are used to characterise the pixel-to-pixel sensitivity;

- the focal plane assembly (FPA) which holds the array detector and the pre-amplifier electronics;

- the PMD unit that contains three broadband PMDs whose spectral bandwidths correspond roughly to the detector array channels 2, 3, and 4 .

ERS-2 orbited the Earth at an altitude of about $790 \mathrm{~km}$ in a Sun-synchronous near-polar orbit; the descending-node local Equator crossing time was about 10:30 UTC, and it had a repeat cycle of 35 days. Each orbit took $\sim 100 \mathrm{~min}$ and the spacecraft completed $\sim 14$ orbits per day. Operational GOME observations are available from July 1995 onwards, although global coverage was lost in June 2003 due to a permanent failure of the ERS-2 on-board tape recorder. Since then availability of GOME data coverage is limited to the region where ERS-2 was in direct contact with ground stations in the European-Atlantic sector. Over the years additional ground stations were brought online to incrementally increase the data-gathering abilities of the satellite. The ERS2 active mission was completed on 4 July 2011 on orbit no. 84719. The ESA mission operations overview (ESA, 2018) provides a detailed review of the most important events over the entire mission lifetime, which may have had an impact on the GOME data quality. Anomalies such as cooler or instrument switch-offs, spectral lamp failures, or data gaps are reported on a yearly basis.

\subsection{GOME Data Processor}

The GOME Data Processor (GDP) is the operational nearreal-time and offline ground segment for the GOME instrument, incorporating, among other things, a level 0-to-1 processing chain (GDP-L1) and the complete GOME data archive (Loyola et al., 1997). During the level 0-to-1 processing, GOME data are converted into calibrated physical quantities by applying a series of calibration algorithms. Some of the calibration data were obtained during the pre-flight on-ground calibration. Other parameters which can be directly derived from measurements using on-board calibration sources are derived during the level 0 -to- 1 processing; they are marked with an asterisk $\left(^{*}\right)$ in the following list. The basic calibration algorithms are as follows: 


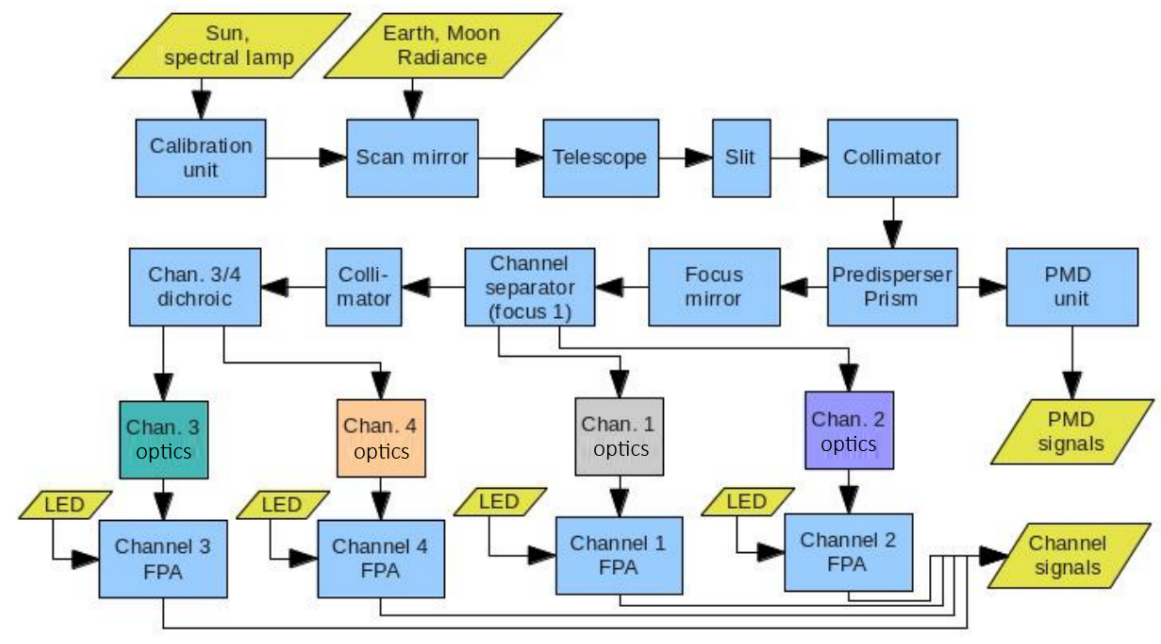

Figure 1. Functional diagram of the GOME instrument (see text for more explanations).

- signal correction, i.e., correction for dark signal*, FPA crosstalk, pixel-to-pixel gain (PPG)* in quantum efficiency, and stray light;

- wavelength calibration*, i.e., assigning to each detector pixel its associated wavelength;

- radiance calibration, i.e., conversion of the corrected detector signals to radiance units by application of the radiance response function (this step also includes the polarisation correction);

- irradiance calibration, i.e., conversion of the corrected detector signals to irradiance units, including the correction for BSDF (bi-directional scattering distribution function) of the diffuser plate;

- geolocation, i.e., determination of the geographical position for each detector readout using ESA's ERS-2 orbit propagator;

- quality assessment, i.e., identification of dead pixels, hot pixels, saturation, and sun-glint.

The GOME on-ground calibration was performed during the pre-flight calibration phase by TPD/TNO (Netherlands Organization for Applied Scientific Research). The output was a data set containing the so-called "calibration key data" such as stray light correction, BSDF coefficients, radiance response function, and polarisation correction. In the course of switching from on-ground to the in-flight situation, various adjustments in the key data had to be applied that were mostly due to air-vacuum wavelength shifts and outgassing of optical coatings. Over the years further updates of the key data have been implemented that were related to the radiance response and to the diffuser BSDF (e.g., Aben et al., 2000; Slijkhuis et al., 2006). An overview of these algorithms using the on-ground calibration data is given in Sect. 3.
Calibration constants which can be directly deduced from measurements using on-board calibration sources (in-flight calibration parameters) are derived during the level 0-to-1 processing. They are fed back immediately to the processor. This comprises the dark signal measurements on the night side of each orbit, the internal LED measurements, and at regular intervals wavelength calibration using the spectral lamp measurements. Figure 2 depicts the processing flow for calculating the respective in-flight calibration parameters including the solar reference measurements. The calibration parameters as well as the SMR spectrum are stored in the calibration database. Monitoring these calibration parameters provides an excellent insight into the long-term stability of the instrument. A detailed description of the corresponding algorithms and the results of the long-term analysis is presented in Sect. 5.

Figure 3 is a flowchart indicating the order of the steps for processing the level 1 science data after the calculation of the calibration data. The individual algorithms are applied to the pre-processed solar data and moon and earthshine measurements. "Normalise" means the normalisation of the signal to $1 \mathrm{~s}$ exposure time. Detailed descriptions of the individual algorithms are presented in Sect. 3 for the on-ground calibration and in Sect. 5 for the in-flight calibration. Another step in the entire calibration procedure is the correction of degradation (see Sect. 4.1). Due to degradation in optical components the calibration parameters for radiance and irradiance change in time. However, this degradation cannot be derived from on-board calibration sources and the correction has to be obtained offline and externally from the data processor. For GOME this has been done by scientific analysis of the solar observations.

The last major GDP-L1 processor update was developed in 2006 in order to provide a first complete reprocessing of the data set available at that time. The main driver for this ac- 


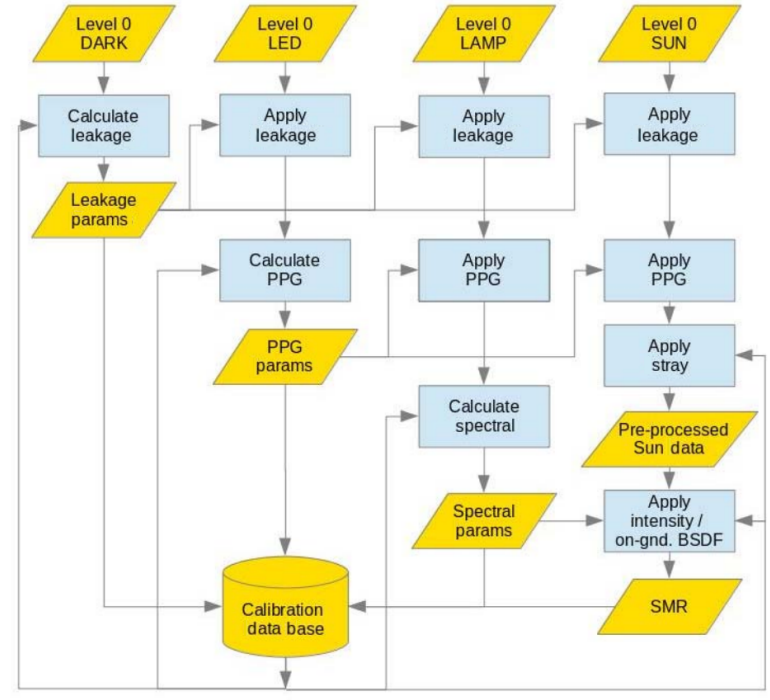

Figure 2. Processing flow for calculating the in-flight calibration parameters from the dark signal measurements (DARK), the internal LED measurements (LED), the spectral lamp measurements (LAMP), and the solar measurements (SUN). The calibration parameters as well as the Sun mean reference (SMR) spectrum are stored in the calibration database.

tivity has been the gaps in the solar calibration spectra over long periods caused by pointing issues on the ERS-2 platform. Furthermore, other algorithmic developments were included and a detailed analysis of the long-term performance of GOME in terms of numerous diagnostic in-flight calibration parameters were performed for the first 11-year period (Coldewey-Egbers et al., 2008).

In the framework of ESA's GOME-Evolution project, the GDP-L1 Version 5.1 has been developed in order to generate a completely homogenised, fully calibrated level 1 product for the entire 16-year mission period. Algorithm improvements comprise a new polarisation correction (Sect. 3.4) and an updated degradation correction (Sect. 4.1), an improved usage of dark signal measurements (Sect. 5.3), and revised and improved spectral calibration (Sect. 5.2).

\subsection{New GOME level 1 product}

The previous GOME level 1 data products, from the predecessor GDP-L1 Version 4.x and lower, contained geolocation, uncalibrated measurements, and all necessary calibration data (and was thus in modern terminology more like a level 1a product). In addition an external post-processing software "extractor" tool was needed to convert these data to calibrated radiances, or to calibrated solar irradiance. The advantages were a small product size and the flexibility for the scientific user to perform sensitivity studies on the impact of different calibration steps. However, in the course of time it has turned out that both arguments are no longer valid.
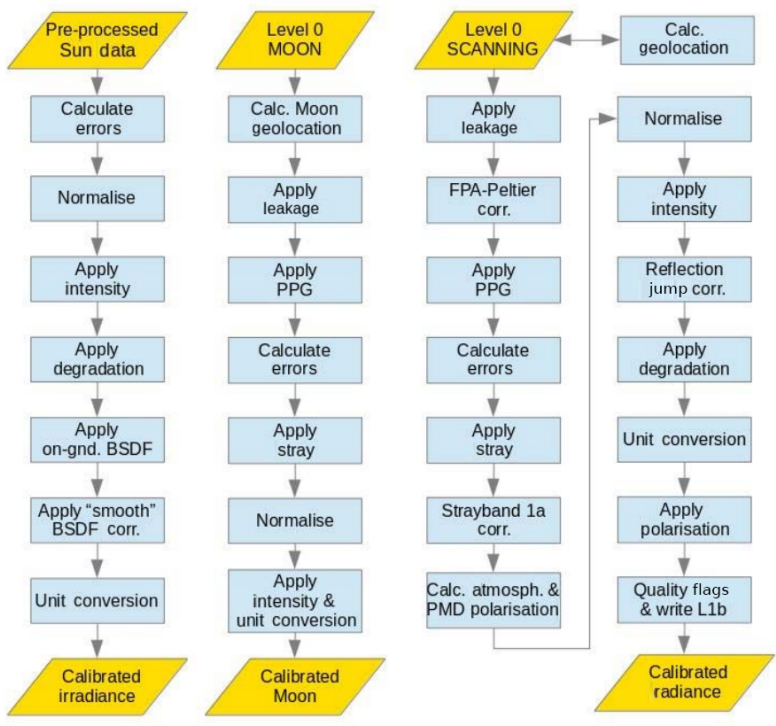

Figure 3. Processing flow indicating the order of steps for calculating the calibrated level 1 science data, i.e., irradiance (left column), moon radiance (middle column), and earthshine radiance (right columns). See text for detailed explanations.

In lieu thereof, the new GOME level 1 product generated with GDP-L1 Version 5.1 contains fully calibrated (ir)radiances, corresponding geolocation information, and selected calibration parameters in NetCDF-4 format. Running a separate extraction tool is not necessary anymore; several former extraction software options are now integrated in GDP-L1, and others are no longer used (Slijkhuis and Aberle, 2016). The product format and structure are designed to be similar to currently developed or planned EO products, in particular to the Sentinel-5 Precursor mission launched in October 2017. This should enable the application of common reading software to the different atmospheric composition sensors with little or no adaptions required for the various products. In addition to radiance and irradiance data, cloud parameters retrieved with the OCRA (Optical Cloud Recognition Algorithm) and ROCINN (Retrieval of Cloud Information using Neural Networks) algorithms (Lutz et al., 2016; Loyola et al., 2018) have been integrated in the new level 1 product, which required reprocessing of the data record in several iterations. Following the request from the users, another addition compared to the old product is geolocation information for each single PMD measurement. A more detailed description of the content and structure of the new level 1 product can be found in Appendix A and in the GOME/ERS-2 Product User Manual (Aberle, 2018). 


\section{GOME on-ground calibration data and correction algorithms}

In this section we provide an overview of the GOME onground calibration data and the basic principles of the corresponding correction algorithms. For more details we refer to Slijkhuis and Aberle (2016).

\subsection{Correction for FPA noise and band 1a residual offset}

Crosstalk correlated to the voltage controlling the Peltier coolers on the focal plane assembly leads to noise on the array detector signal that varies slowly with time. It can be approximated by multiplying the Peltier cooler control signal by a scaling factor that has been obtained during the commissioning phase (April 1995 to July 1996) from one typical orbit and is stored in the calibration key data file. The noise is correlated to the integration time and correction is only necessary for integration times of $6 \mathrm{~s}$ or longer, typical for band 1a measurements. Furthermore, the correction is only applied to earthshine measurements. The correction algorithm comprises four steps: (i) apply a high-pass filter to all Peltier output signals belonging to channel 1 from one orbit, (ii) calculate an average value of the filtered Peltier output, (iii) multiply the mean Peltier output by the scaling factor specified for the actual integration time, and (iv) subtract the noise from the signals of the entire band to be corrected.

It appears that after the removal of the Peltier noise as described above, a residual offset remains that has to be corrected since it is too large for, for example, ozone profile retrieval. This additional correction has been developed in the framework of the CHEOPS-GOME study (Slijkhuis, 2006; Slijkhuis et al., 2006) and is implemented in the L1 processor. It uses the signal of the stray light band 1a (just before the beginning of the nominal band 1a).

\subsection{Stray light correction}

After the first calibration and characterisation measurements of GOME at TPD/TNO, it became obvious that stray light, i.e., light from wavelengths other than the nominal wavelength of a specified detector pixel, is a major issue and needs to be corrected during the $\mathrm{L} 1$ processing. In order to reduce the impact of stray light, several improvements were applied before launch such as tilt changes to the gratings, the use of anti-reflection coatings, change of the channel separation between channel 1 and 2, and improvement of internal baffling. Despite these improvements a correction algorithm is still required. Specifically in channels 1 and 2 the signal readouts are spoiled by a non-negligible amount of stray light whose main sources are as follows:

- a uniform or very slowly changing quantity of stray light over the detector pixels induced by diffuse reflections within the FPA;
- ghost stray light signals induced by reflections from the surfaces of the detector arrays and the lenses of the channel telescope - symmetrical ghosts (signals mirrored at the middle of the detector) and asymmetrical ghosts (signals mirrored at some arbitrary detector pixel) were detected;

- out-of-band stray light on the PMDs induced by radiation outside the wavelength range of the detector arrays.

Summed contributions from uniform and ghost stray light are subtracted from the measured signal. The relative uniform stray light levels obtained during the pre-flight calibration are $0.2 \%$ for channels 1 and 2 and $0.1 \%$ for channels 3 and 4 . These levels are multiplied with the averaged signal fluxes per detector array to get the uniform stray light contribution. For GOME, there is only one significant ghost. Its efficiencies $(0.05 \%$ for channels 1,2 , and 4 and $0.1 \%$ for channel 3 ) were determined during the pre-flight characterisation and are multiplied with the mirrored (around the pixel centre of the ghost) signal flux to get the ghost stray light contribution. However, the calibration key data for stray light are probably not more accurate than $\sim 10 \%$, i.e., processing errors of $10 \%$ of true stray light.

\subsection{Radiometric calibration}

The objective of the radiometric calibration is to transform the 16-bit binary units (BU) of the detector pixel readouts into calibrated radiances (photons $\mathrm{s}^{-1} \mathrm{~cm}^{-2} \mathrm{~nm}^{-1} \mathrm{sr}^{-1}$ ) or, for the Sun, into calibrated irradiance (photons $\mathrm{s}^{-1} \mathrm{~cm}^{-2} \mathrm{~nm}^{-1}$ ). In GDP-L1 the radiometric calibration is divided into several steps (see also Fig. 3).

The radiance response function, which depends on wavelength, scan angle, and temperature, is applied to the solar, moon, and earthshine measurements. It is a compound function in which the scan-angle-dependent part and the temperature-dependent part are given per channel, for 9 scan angles and for 5 temperatures, respectively. These key data are then interpolated to the actual values of the respective measurement. Then, solar and earthshine spectra are corrected for instrument degradation (see Sect. 4.1).

The BSDF correction is applied to the solar measurements and comprises two parts. The basic BSDF from the on-ground calibration depends on wavelength, azimuth angle, and the elevation of the sunlight on the diffuser. It is expressed as parameterisation using polynomials. The second step uses an improved azimuth dependence of the diffuser BSDF (Slijkhuis et al., 2006). The azimuth dependence is fitted using a third-order polynomial in wavelength for all channels. The polynomial coefficients are stored in a lookup-table for a number of azimuth angles that are then linearly interpolated to the actual angle.

The earthshine radiance is additionally corrected for the so-called "radiance jump" effect that is caused by the serial readout of the detector, i.e., the last pixel of the array 
is read out $93.75 \mathrm{~ms}$ later than the first pixel. In the case of inhomogeneous ground scenes this effect may be visible as a jump in radiance between two neighbouring detectors. The last pixels of one detector record the same wavelengths as the first pixels of the next channel, but at an integration time shifted by $93.75 \mathrm{~ms}$. A linear correction in wavelength is applied which re-normalises all intensities to the same integration time, thereby using information from the PMDs (which are read out every $93.75 \mathrm{~ms}$ synchronised with the first detector pixel). Although the correction adjusts the continuum level, it cannot account for any difference in spectral features that may arise from viewing a slightly different ground pixel. For earthshine measurements the intensity calibration also includes the application of a polarisation correction (see Sect. 3.4).

\subsection{Polarisation correction}

GOME is a polarisation-sensitive instrument. The radiance response function described in Sect. 3.3 calibrates the instrument assuming unpolarised light. Therefore a correction factor must be applied that describes the ratio of the throughput for actual input polarisation to the throughput for unpolarised light. The polarisation correction algorithm (PCA) needs the polarisation sensitivity of the instrument as well as a characterisation of the atmospheric polarisation. It is divided into two main parts, which both use on-ground key data. The first step is to derive the atmospheric polarisation from theory and from measurement for a few wavelengths. Three of these polarisation points come from the comparison of channel array signals with broadband PMD signals; the corresponding wavelengths are approximately 360,500 , and $700 \mathrm{~nm}$. A fourth point is obtained from theoretical assumptions and comes from a Rayleigh single-scatter model simulation of polarisation in the UV. The second step of the PCA is to interpolate the polarisation points to wavelength and to apply the correction to the whole spectrum. Below $\sim 300 \mathrm{~nm}$, polarisation is taken as a constant. The exact wavelength and the polarisation value are calculated based on a Rayleigh single-scattering model. In the UV region $300-315 \mathrm{~nm}$ the generalised distribution function (GDF) is used, which is parameterised as function of albedo and ozone content (GDF, Schutgens and Stammes, 2002) is used. From the wavelength where the GDF starts to flatten out, at $\sim 315 \mathrm{~nm}$, the GDF is smoothly connected to the polarisation points from the PMDs, using Akima interpolation for the better part of the spectrum longward of $315 \mathrm{~nm}$ (Slijkhuis and Aberle, 2016). The impact of the polarisation correction on the spectra is of the order of $-1 \pm 5 \%$. The largest change $(-5 \pm 12 \%)$ arises in band $1 \mathrm{~b}(283-316 \mathrm{~nm})$ and the minimum impact is found in channel $4(-0.5 \pm 0.5 \%)$.

Within GOME-Evolution one important improvement for the GDF parameterisation has been implemented: that is to use GOME's own retrieved total ozone columns instead of climatological ones. To this end the level 2 ozone values are inserted into the level 1 calibration database. This was hardly possible during the operational phase of the instrument, but for reprocessing there was no limitation, especially because the ozone retrieval is not critically dependent on the polarisation curve itself, i.e., within the accuracy needed for this parameterisation. Thus, in principle no iterations between level 1 processing and level 2 processing are necessary. Nevertheless, in practice these iterations were made in the course of several intermediate re-processings so that ozone columns used for the final version are fully compatible with the level 1 polarisation.

\section{Solar irradiance, PMD measurements, and reflectance}

In this section we present the long-term evolution of the solar irradiance, PMD, and reflectance measurements. Monitoring the irradiance (Sect. 4.1) was used to develop a firstorder degradation correction algorithm that is routinely applied in GDP-L1 to irradiance and radiance data. Differences between the irradiance and radiance degradation due to different light paths and a strong scan angle dependence are analysed later in Sect. 4.3.

\subsection{Sun mean reference spectrum and degradation correction algorithm}

Once per day GOME recorded a short series of Sun spectra via the solar port and a diffuser plate. Thereby, the incidence angle on the diffuser is (i) constant in azimuth (which varies only with season) and (ii) changes in elevation as the Sun moves through the field of view. The incidence angle of the scan mirror is $41^{\circ}$ (compared to $49^{\circ} \pm 15^{\circ}$ for the nadir measurements). All measurements within an elevation angle of $\pm 1.5^{\circ}$ with respect to the centre are averaged and corrected for the azimuth dependence of the diffuser BSDF (see Sect. 3.3). This yields the so-called daily SMR spectrum, which is stored in the calibration database and used for the calculation of the earthshine reflectivity spectra. The latter serve themselves as input for almost all retrieval algorithms for atmospheric constituents as well as cloud and aerosol properties.

The relative intensity of the GOME SMR spectra with respect to a reference spectrum from 3 July 1995 is depicted in Fig. 4 (January 1996 to January 2011, one spectrum per year) to demonstrate the severe impact of degradation of the optical properties. This comparison shows that the pre-flight radiance parameters were no longer applicable to the in-flight situation (Aben et al., 2000; Hegels et al., 2001). The main degradation as a consequence of extensive exposure to the space environment can be attributed to deposits on the scan mirror (which is coated with a $\mathrm{MgF}_{2}$ layer), thereby changing its reflective properties. Degradation due to changes related to the diffuser were declared to be negligible (Snel, 
2001). The loss in throughput is especially severe in channel 1. Below $300 \mathrm{~nm}$ intensity decreased by $80 \%-95 \%$, which implies a significant deterioration of the signal-to-noise ratio. Table 1 indicates the approximate signal-to-noise ratios for typical radiance values for channel 1 at 290 and $305 \mathrm{~nm}$, channel 2 above $325 \mathrm{~nm}$, and channels 3 and 4 at the beginning, in the middle, and at the end of the GOME mission, respectively. For channels 2, 3, and 4, the signal-to-noise ratio is well above 1000 . Towards shorter wavelengths the ratio significantly decreases due to strong ozone absorption and a weaker solar irradiance. These values are comparable to those obtained for SCIAMACHY (Bovensmann et al., 1999, their Fig. 4). In channel 1 (and also in the other channels) the signal-to-noise ratio for GOME is expected to decrease linearly with the degradation of the signal (for signal levels below $\sim 15000 \mathrm{BU}$ ) since the detector noise is exceeding the shot noise. Above signal levels of $\sim 15000$ BU shot noise becomes dominant. Thus, the strong degradation observed in channel 1 may have a severe impact on the retrieval of atmospheric parameters using this specific spectral region, e.g., ozone profiles (van Peet et al., 2014). The decrease in channel 2 is $40 \%-80 \%$. In channel 3 the decline (10\%-40\%) started in 2001. Throughput changes in channel 4 are relatively small. Values above 1 might be due deposits on the coatings which can lead to changes in interference patterns and an increase in intensity (Snel, 2001). Since mid-2001 the measurements were additionally affected by an ERS-2 pointing problem as a consequence of the loss of the gyroscopes' (which govern the platform steering) functionality. SCIAMACHY as well as GOME-2 suffer from degradation in pretty much the same way (Noël et al., 2007; Bramstedt et al., 2009; Munro et al., 2016), whereas OMI irradiances degraded by only 3\%-8\% from 2005 to 2015 (Schenkeveld et al., 2017).

In Fig. 4 at wavelength regions around 470 and $600 \mathrm{~nm}$, changes in intensity are affected by changes (outgassing of coatings) in the dichroic filter which separates the wavelengths of channels 3 and 4. Unpredictable polarisationsensitive changes were observed and the radiometric calibration in these regions might be doubtful. Furthermore the outgassing is assumed to be responsible for the slight transmission increase in channel 3 in the early part of the mission. The low-frequency oscillating structure appearing in all channels is the result of the etalon effect which is caused by a changing thickness of ice deposits on the detectors and which leads to spectral interference patterns (Mount et al., 1992). At present no attempts are being made to correct for this effect.

In order to remediate the observed GOME science channel degradation, a correction algorithm was developed in the framework of the ESA project GDAQI (GOME Data Quality Improvement, Aben et al., 2000). This degradation correction is applied to irradiance and radiance spectra as an additional part of the radiometric calibration. The degradation correction approach that was chosen is the comparison of all available solar data from the entire mission period with

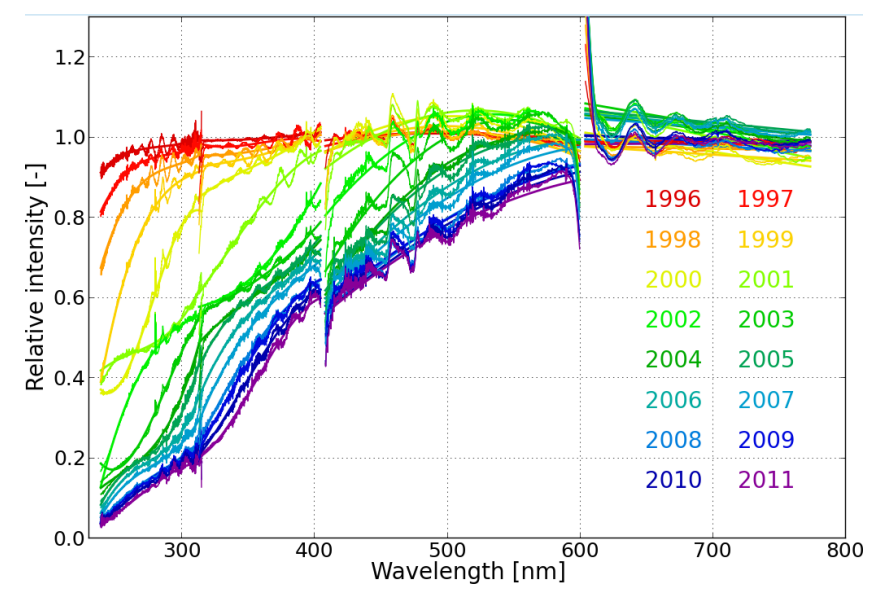

Figure 4. Relative intensity of GOME Sun mean reference spectra (January 1996 to 2011, one spectrum per year) with respect to a reference spectrum from 3 July 1995. Corresponding smooth solid lines denote results of the polynomial fit performed during the degradation correction. Wavelength regions around 470 and $600 \mathrm{~nm}$ are affected by changes (outgassing) in the dichroic filter (see text for more details).

the corresponding solar data of a reference day in the early GOME lifetime (3 July 1995). The Sun is a reliably stable input source to monitor the instrument throughput despite small changes in the solar spectrum due to changes in solar activity. This study was done for both the GOME science channels and the PMDs. The temporal changes have been determined by building ratios of all solar spectra with the solar spectrum of the reference day $t_{0}$, which may be written as

$$
\frac{I_{\text {Sun }}(\lambda, t)}{I_{\text {Sun }}\left(\lambda, t_{0}\right)}=P_{\text {Deg }}(\lambda, t) \cdot C_{\mathrm{SED}}(t) \cdot \operatorname{Residual}(\lambda, t),
$$

where $P_{\text {Deg }}(\lambda, t)$ is the degradation function used and is dependent on wavelength $\lambda$ and time $t . C_{\mathrm{SED}}(t)$ is the intensity correction due to the seasonal variation in Sun-Earth distance, and $\operatorname{Residual}(\lambda, t)$ is the remaining structure. Note that the impact of the etalon effect and the changes in the dichroic filter are not accounted for. For the determination of the degradation correction function $P_{\mathrm{Deg}}(\lambda, t)$, a two-step approach was developed: (i) each irradiance ratio (per channel) is approximated by a polynomial function in wavelength and (ii) each coefficient of this polynomial in wavelength is subsequently described by a time-dependent expression. Thus, for the degradation function $P_{\operatorname{Deg}}(\lambda, t)$ per channel the following expression has been obtained:

$P_{\text {Deg }}(\lambda, t)=\sum_{k=0}^{n} a_{k}(t) \cdot\left(\lambda-\lambda_{0}\right)^{k}$.

$\lambda_{0}$ is the centre wavelength in each channel. Each coefficient $a_{k}(t)$ of the polynomial in wavelength is taken from a look-up table (LUT). For channels 1 and 2, third-order polynomials $(n=3)$ are used, whereas in channels 3 and 4 
Table 1. Approximate signal-to-noise ratios at the beginning, middle, and end of the GOME mission for five spectral regions. * Note that the values for channel 1 in 1995 are for an integration time of $6 \mathrm{~s}$ whereas the other values are for an integration time of $1.5 \mathrm{~s}$.

\begin{tabular}{lccccc}
\hline Spectral region & $\begin{array}{c}\text { Channel 1 } \\
\text { at 290 nm }\end{array}$ & $\begin{array}{c}\text { Channel 1 } \\
\text { at 305 nm }\end{array}$ & $\begin{array}{c}\text { Channel 2 } \\
\geq 325 \mathrm{~nm}\end{array}$ & Channel 3 & Channel 4 \\
\hline Radiance (photons s ${ }^{-1} \mathrm{~cm}^{-2} \mathrm{~nm}^{-1} \mathrm{sr}^{-1}$ ) & $\sim 3.0 \times 10^{10}$ & $\sim 4.0 \times 10^{11}$ & $\sim 2.0 \times 10^{13}$ & $\sim 3.0 \times^{13}$ & $\sim 3.0 \times 10^{13}$ \\
Signal-to-noise: 1995 & $\sim 140^{*}$ & $\sim 1100^{*}$ & $\sim 3500$ & $\sim 4000$ & $\sim 2500$ \\
2001 & $\sim 20$ & $\sim 180$ & $\sim 2700$ & $\sim 4000$ & $\sim 2500$ \\
2010 & $\sim 6$ & $\sim 55$ & $\sim 1600$ & $\sim 3500$ & $\sim 2500$ \\
\hline
\end{tabular}

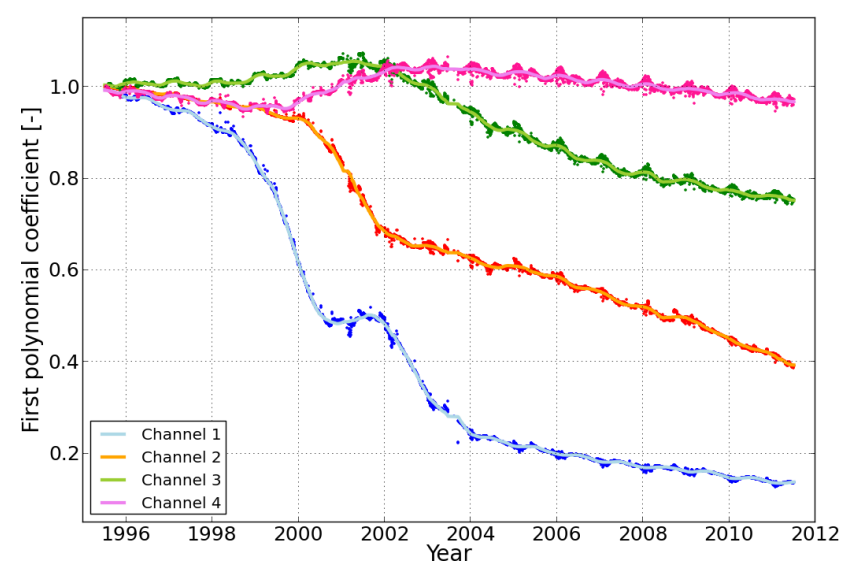

Figure 5. First polynomial coefficient $a_{0}$ from wavelength fit as a function of time (small dots, blue: channel 1, red: channel 2, green: channel 3, and magenta: channel 4). The light blue, orange, light green, and light violet curves denote the corresponding smoothed curves using a Savitzky-Golay smoothing filter with a filter width of 250 days.

quadratic $(n=2)$ and linear $(n=1)$ polynomials are used, respectively (see smooth curves in Fig. 4). The LUT is generated by smoothing the time series of each polynomial wavelength coefficient using a Savitzky-Golay filter (Press et al., 1992) with a filter width of 250 days. Figure 5 shows, for each channel, the first polynomial coefficient $\left(a_{0}\right)$ and the corresponding smoothed curve as a function of time. In channel 1 degradation started almost immediately after launch. Until 2000 the intensity decreased to $\sim 50 \%$ of the earlymission values. In channel 2 significant decrease in intensity is observed, especially during 2000-2002. Since mid-2001 all measurements were additionally affected by the ERS-2 pointing problem. Furthermore, channels 3 and 4 are affected by changes in the dichroic filter, i.e., outgassing of coatings.

In GDP-L1 the degradation correction is then applied according to the following:

$I_{\text {SunCorr }}(\lambda, t)=I_{\text {Sun }}(\lambda, t) / P_{\operatorname{Deg}}(\lambda, t)$.

In addition to the Sun the moon provides an independent irradiance source and in principle GOME lunar measurements can be used to characterise and monitor instrument performance and degradation (Dobber, 1997; Dobber et al., 1998). The moon is viewed on the eclipse side of the orbit over the scan mirror at an incidence angle of $5^{\circ}-15^{\circ}$. The amount of light is of the same order of magnitude as for the earthshine observations, though calibration measurements are complicated by several factors such as moon availability and phase, non-uniformity of the moon surface, polarisation, and partial slit filling. Orbit requirements were so strict that measurements are only possible for a very limited number of orbits per year, with the moon phase always being $\sim 0.6$ between the full moon and the last quarter. After 2003 no more moon measurements are available. Thus, GDP-L1 does not attempt to generate calibrated radiances for the moon, and a long-term analysis of moon observations has not been performed. Furthermore, for an accurate monitoring of instrument degradation using lunar measurements, a more precise characterisation of the reflective and scattering properties of the moon would be necessary. However, early investigations by Dobber (1997) using the first 18 months of GOME's lifetime confirmed the assumption that the scan mirror (instead of the diffuser) is primarily subject to degradation.

\subsection{PMD measurements and Q_factors}

The relative change of the solar PMD measurements as a function of time with respect to a reference measurement from 3 July 1995 are shown in Fig. 6 for all three PMDs. Note that the measurements were normalised to 1 astronomical unit (AU) in order to eliminate seasonality. As for the SMR spectra the degradation for the PMDs is strongest for PMD 1 , which corresponds to channel 2 . The signal decreases to about $40 \%$ of the original value. The temporal evolution for PMDs 2 and 3 is similar to the behaviour of the signals in channels 3 and 4, respectively.

PMD Q_factors are self-calibration constants which ensure that the calculated fractional polarisation $p$ of the Sun is unpolarised with $p=0.5$. They are defined as the relative difference between the measured solar signal of $\mathrm{PMD}_{i}$, with $i=1,2,3$, and the expected PMD signal calculated from the key data and the corresponding channel signals, when unpo- 

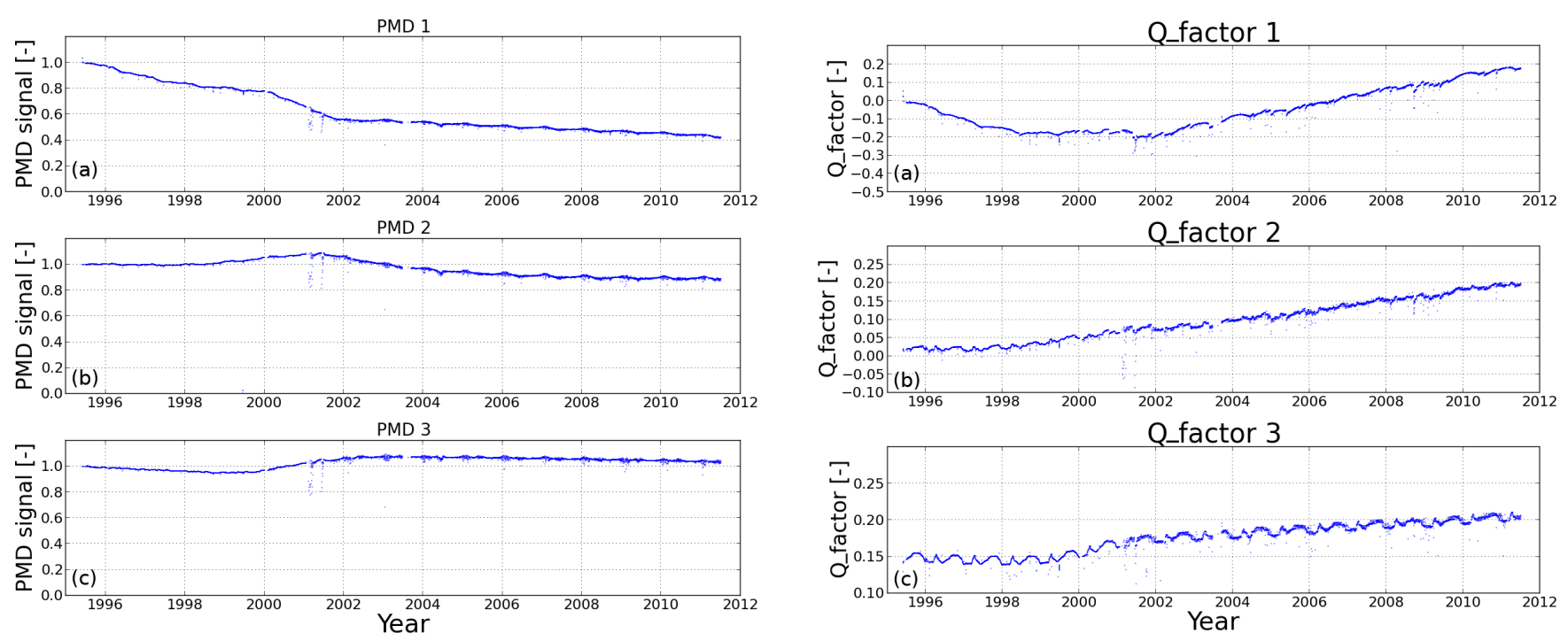

Figure 6. Relative change of PMD signals as a function of time from 1995 to 2011 for PMDs 1, 2, and 3 (a-c). Reference measurement is from 3 July 1995.

larised input is assumed to be as follows:

Q_factor ${ }_{i}=\left(\mathrm{PMD}_{i}-\sum_{j} X_{j} \times\right.$ channel $\left._{j}\right) / \mathrm{PMD}_{i}$,

where channel ${ }_{j}$ is the channel signal of pixel $j$ and $X_{j}$ is the ratio of the PMD signal to the channel signal for a monochromatic input signal as obtained from on-ground calibration measurements. Q_factors thus involve the differential degradation between PMD signals and the channel signals since the time of on-ground calibration.

Figure 7 shows the Q_factors for PMD 1, 2, and 3 (from top to bottom) as a function of time from 1995 to 2011. In principle, the behaviour of the Q_factors as detected in the previous study (Coldewey-Egbers et al., 2008) continued. For the first Q_factor a decrease until 2001 is observed. From 2002 to 2011 Q_factor 1 steadily increased. That means that in the first period the degradation of the PMD signal was stronger than the degradation of the signal in channel 2 , whereas in the second period the channel signal decreased faster then the PMD signal. Q_factor 2 increased slowly from the beginning of the measurements - indicating that the PMD signal degraded less than the average signal in channel 3 and reached nearly the same value as Q_factor 1 at the end of the mission. For Q_factor 3 note that it is already nonzero at the beginning of the measurements. This is related to stray light (wavelength $>790 \mathrm{~nm}$ ), which affected in particular PMD 3, whereas PMD 1 had a negligible stray light effect. Q_factor 3 remained more or less stable until 1999 followed by a slow increase until 2011. Outliers are due to GOME operation anomalies such as cooler switch-offs, instrument or satellite switch-offs, on-board anomalies, or special operations (see also ESA, 2018).

Figure 7. Q_factors 1, 2, and 3 (a-c) as a function of time from 1995 to 2011.

\subsection{Reflectance degradation}

In Sect. 4.1 the approach used to correct for instrument degradation was described. This "soft" correction is a firstorder correction as it is applied in GDP-L1 to both irradiance and radiance spectra, thereby assuming that both spectra degrade in the same way. The ratio

$R=\frac{\pi I}{\mu_{0} E}$,

where $I$ is the top-of-atmosphere (TOA) radiance reflected and scattered by the Earth's atmosphere, $E$ is the solar irradiance, and $\mu_{0}$ is the cosine of the solar zenith angle, defines the reflectance $R$, which is used by many algorithms to retrieve the amount of atmospheric constituents. From Eq. (5) it is clear that the reflectance remains unchanged in the level 0-to-1 processing since the applied degradation correction cancels out under the assumption that the BSDF does not degrade. However, the light paths for radiance and irradiance measurements are different and the degradation of the scan mirror indicates a strong dependence on the incidence angle (Snel, 2001). This leads to a substantial differential degradation of radiance and irradiance spectra (Tanzi et al., 2001; van der A et al., 2002) and, thus, to degradation in the reflectance, which may affect for example ozone profile retrievals (van der A et al., 2002; Liu et al., 2007) or the determination of total ozone columns using a direct fitting approach (Lerot et al., 2014), because these algorithms are sensitive to absolutely calibrated reflectances. Correction approaches for the reflectance degradation have been developed in the past which rely on, for example, the comparison of experimental and simulated data (van der A et al., 2002; Cai et al., 2012), the comparison of satellite reflectance spectra with ground-based reference spectra (Lerot et al., 2014), 
or the comparison of global average reflectance with respect to global average reflectance from the beginning of the mission (Liu et al., 2007; Tilstra et al., 2012). For the latter approach the underlying assumption is that the global average reflectance does not change in time. For irradiance degradation correction (see Sect. 4.1) this assumption can be regarded fulfilled, but the earthshine radiance and, thus, the reflectance depend strongly on highly variable atmospheric conditions such as clouds, trace gases, aerosols, or surface albedo and on the viewing angle. Therefore, retrievals using this correction may be inadequate for trend studies (Liu et al., 2007). However, Garane et al. (2018) have shown that when using the latest version of the direct fitting approach GODFIT for ozone retrieval (GODFIT version 4), GOME (as well as $\mathrm{OMI}$ ) performs in an extremely stable way.

In the framework of GOME-Evolution we analysed the long-term behaviour of the GOME reflectance using measurements over so-called pseudo-invariant calibration sites (PICSs) which have been identified and characterised by the Committee on Earth Observation Satellites (CEOS) to be suitable for detecting the radiometric stability of satellite sensors (USGS, 2018). The advantages of these sites are the spatial uniformity and homogeneity, their stable spectral characteristics over time, and generally high reflectance to enhance the signal-to-noise ratio. At the moment there are six CEOS reference PICSs, all located in the Saharan desert: Libya-1 and Libya-4, Mauritania-1 and Mauritania-2, and Algeria3 and Algeria-5. They are usually made up of sand dunes with climatologically low aerosol loading, little rainfall, and practically no vegetation or human impact. More details on the PICSs can be found in Helder et al. (2010). In the past these sites have been widely used in post-launch calibration and validation of satellite sensors (e.g., Smith and Cox, 2013; Mishra et al., 2014; Sun et al., 2014; Uprety and Cao, 2015).

For our study we selected four reference sites: Libya$1\left(24.42^{\circ} \mathrm{N}, 13.35^{\circ} \mathrm{E}\right)$ and Libya-4 $\left(28.55^{\circ} \mathrm{N}, 23.39^{\circ} \mathrm{E}\right)$ as well as Algeria-3 $\left(30.32^{\circ} \mathrm{N}, 7.66^{\circ} \mathrm{E}\right)$ and Algeria-5 $\left(31.02^{\circ} \mathrm{N}, 2.23^{\circ} \mathrm{E}\right)$. The geolocation in the parentheses denotes the centre latitudes and longitudes. Fortunately, in this area the impact of the ERS-2 tape recorder failure in June 2003 is quite small, so that the time series are almost complete with only a short gap in 2003. We limit our analysis to two single wavelengths in the UV part of the spectrum (325 and $335 \mathrm{~nm}$ ), which mark the lower and upper limit of the fitting window for total ozone retrieval (Loyola et al., 2011; Lerot et al., 2014). All GOME ground pixels with cloud fraction less than 0.2 that fall into a square area of $\pm 1.5^{\circ}$ in latitude and longitude around the centre geolocation of the reference site were extracted. About 3000 ground pixels were found for each reference site that fulfill these criteria. In general, the top-of-atmosphere reflectance of a scene measured by the satellite sensor depends on the viewing geometry because of the anisotropy of the surface reflectance. The reflectance is higher for west pixels, when the Sun and the satellite are on the same side of the scene (backward- scattering viewing geometry), than for east pixels in forwardscattering viewing geometry (Zoogman et al., 2016; Lorente et al., 2018). The anisotropy depends on wavelength and on the surface properties. In the case of the Saharan PICS scenes and for wavelengths of 325 and $335 \mathrm{~nm}$, the difference in reflectance between west and east pixels is about $25 \%$.

Figure 8 shows the reflectance normalised to the reflectance at the beginning of the mission, segregated by pixel type (east, nadir, and west, which mark the three forward scans) for both wavelengths (solid curves denote $325 \mathrm{~nm}$ and dashed curves denote $335 \mathrm{~nm}$ ) as a function of time for the entire mission for PICS Libya-4. The data gap from mid-2003 to early 2004 is due to the tape recorder failure. Fluctuations in reflectance related to the seasonal variation and to short-term variation of atmospheric conditions were smoothed out. Until late 1999 the curves show only a small amount of degradation. Afterward they start to increase, reach a maximum in 2001, and then decrease again to values below 1 in early 2003. From 2004 to 2011 the curves steadily increase except for the reflectance degradation for west pixels at $325 \mathrm{~nm}$ (solid cyan curve), which show a slight decrease at the very end of the mission. These ups and downs in the degradation might be related to changes in interference patterns, which can lead to an increase or decrease in reflectance. Furthermore, the degradation depends strongly on the pixel type, i.e., the line of sight. Until 2003 west pixels are much less affected than nadir and east pixels, and also after 2003 the behaviour of the reflectance from west pixels is slightly different compared to nadir and east pixels. For the other three PICSs (Libya-1, Algeria-3, and Algeria5 ) we found very similar results (no figure) with negligible differences compared to Libya-4. In addition, we analysed the reflectance for cloud-free pixels over the Mediterranean Sea between Greece and Egypt, which shows the same temporal evolution as the reflectance over the Saharan desert (no figure) although the surface albedo is much lower there. As mentioned earlier, in principle this analysis could be used for correcting the reflectance degradation. However, the underlying requirement that the reflectance remains stable over a long time period might not be fulfilled in every case.

\section{GOME in-flight calibration parameters}

In this section we present the analysis of the GOME calibration parameters obtained from measurements using on-board calibration sources and applied during the level 0-to-1 processing as described in Sect. 2.2. For a detailed description of the individual calibration algorithms related to the parameters we refer to the GOME Algorithm Theoretical Basis Document (Slijkhuis and Aberle, 2016). Monitoring of the individual parameters was performed with special emphasis on the analysis of the long-term stability. 


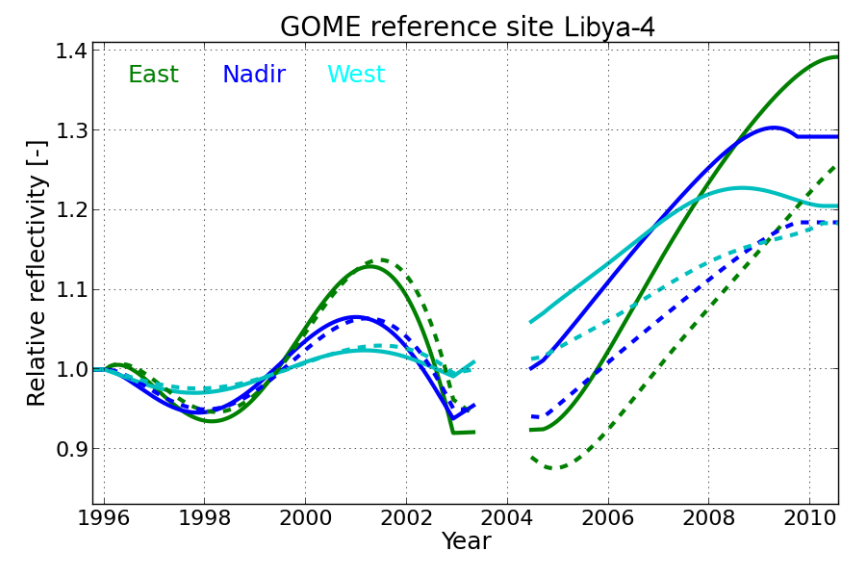

Figure 8. Relative reflectivity as a function of time for cloud-free GOME measurements at $325 \mathrm{~nm}$ (solid) and at $335 \mathrm{~nm}$ (dashed) for the Libya-4 reference site. Colours denote the different GOME pixel types: east (green), nadir (blue), and west (cyan) ground pixels. The data gap between mid-2003 and early 2004 is due to the ERS-2 onboard tape recorder failure in June 2003.

\subsection{Overview}

In the framework of the GOME-Evolution project the complete set of in-flight calibration data has been revisited and re-analysed in order to draw conclusions on the long-term stability of the GOME sensor and to optimise the GDPL1 usage of the in-flight calibration for the entire mission. The database contains spectral lamp measurements for the wavelength calibration (see Sect. 5.2), dark current measurements for all integration time patterns (see Sect. 5.3), and LED measurements for the pixel-to-pixel gain correction (see Sect. 5.4), as well as the Sun mean reference spectra and moon and PMD measurements. After the ERS-2 tape recorder failure in June 2003 the number of available calibration data is significantly reduced, since only data within accessibility of an ERS-2 receiving station were transmitted to ground. In particular, no more moon measurements are available after 2003.

\subsection{Spectral calibration}

The objective of the spectral calibration is to assign a certain wavelength to each individual GOME detector pixel. Therefore, the instrument houses a platinum-chromium-neon hollow cathode emission lamp (Murray, 1994). This lamp provides a sufficient number of atomic emission lines of these three elements with well-known spectral positions that allow the wavelength allocation. At first, spectral calibration parameters are calculated by the determination of the pixel number centre of the spectral lines and the subsequent fitting of a polynomial through these pixel-wavelength pairs. The second step is the application of the calibration parameters from the previous step to the measurements.
Several lamp spectra were measured (i) over the orbit approximately once per month, during the calibration timeline that was run for five orbits, and (ii) every day just before and after the Sun calibration. The latter measurements are available until April 1998. Since September 2001 the calibration lamp was used only during the five orbits of the monthly calibration due to numerous lamp failures caused by the voltage not having reached its nominal value (see also ESA, 2018).

For the spectral calibration a total of 68 candidate emission lines within GOME's spectral range from 240 to $790 \mathrm{~nm}$ were selected from the reference lamp atlas (Murray, 1994) and are stored in the calibration key database. The lamp measurements of the individual lines can be regarded as statistical distributions from which the moments can be calculated. They contain characteristic information about the spectral lines that are needed to select those lines suitable for an accurate calibration. The aforementioned moments are the mean value, i.e., the pixel number centre of the maximum intensity, as well as the variance, the standard deviation $\sigma$, and the skewness. The full-width half-maximum (FWHM) is computed from the standard deviation. To be selected, the moments of a spectral line must meet the following statistical criteria: (i) the signal of the centre pixel shall not be below a certain minimum, i.e., it should be well above the noise level; (ii) the FWHM shall not be below a certain value in order to fulfill the Nyquist criteria for the digital recording of analogue signals; and (iii) the skewness shall not be larger than a certain value, i.e., the line must be roughly symmetrical. Reasonable thresholds for the criteria have been determined during the pre-flight measurements and the commissioning phase. Current values are $50 \mathrm{BU} \mathrm{s}^{-1}$ for channel 1 and $300 \mathrm{BU} \mathrm{s}^{-1}$ for channels $2-4$ for the first criterion, $\sigma \geq 0.6$, FWHM $\geq 1.5$ pixel, and skewness $\leq 0.6$ for the second and third criterion.

As mentioned before, the calibration parameters are obtained by fitting a polynomial through the pixel-wavelength pairs. In channels 1 and 2 third-order polynomials are used, whereas in channels 3 and 4 fourth-order polynomials are used. At least seven spectral lines per channel are needed for the fit, which is performed using the singular value decomposition algorithm (Press et al., 1992).

The statistical parameters of each individual emission line were analysed in terms of both long- and short-term stability. Regarding short-term variability, few lines were found whose moments show jumps between two values leading to jumps in the fitted polynomial coefficients. Other lines fulfill the aforementioned criteria only in very few cases, which also results in jumps in the fitted coefficients. This analysis has led to a revised spectral line list (by excluding the identified unstable lines) that improved the stability of the spectral calibration for the complete mission. Figure 9 shows the wavelength changes of selected lamp lines (two per channel) as a function of time. Depicted is the difference (in $\mathrm{nm}$ ) with respect to the wavelength at the beginning of the mission. The stability of the wavelengths is excellent until 2004. Toward 

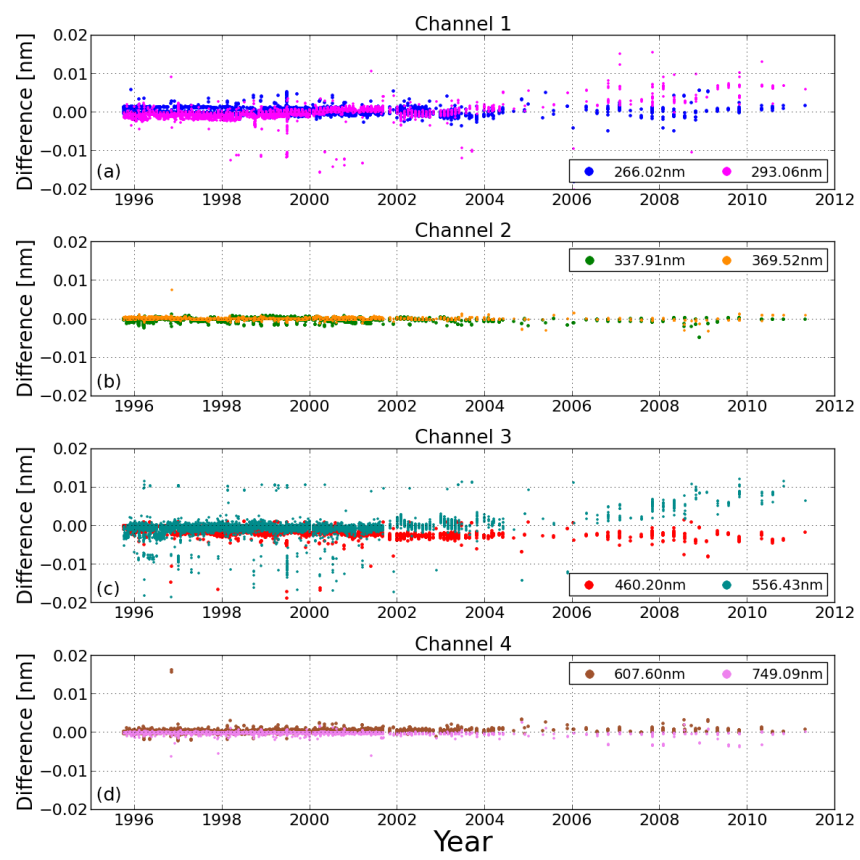

Figure 10. Temperature measured at the pre-disperser prism as a function of time from 1995 to 2011 (blue) and linear fit (red). The temperature increase is about $2.5 \mathrm{Kdecade}^{-1}$. Magenta dots denote the increase in the pre-disperser temperature along one orbit in Kelvin $\mathrm{h}^{-1}$ (right $y$ axis) for the years 1995 to 2003. Analysis of later years is not possible due to the tape recorder failure (incomplete orbits).

Figure 9. Change in wavelength (with respect to the beginning of the mission) as a function of time from 1995 to 2011 for two selected lamp lines per channel. From (a) to (d): channel 1, channel 2, channel 3, and channel 4 .

the end of the mission the variability increases slightly, in particular in channels 1 and 3 . The standard deviation of the wavelength changes is $0.0015 \mathrm{~nm}$ in channel $1,0.0025 \mathrm{~nm}$ in channel 3, and less than $0.001 \mathrm{~nm}$ in channels 2 and 4 . These values are comparable to the analysis by van Geffen (2004), who used a different wavelength calibration approach (van Geffen and van Oss, 2003). They found temporal variations of the wavelength calibration from 0.0015 to $0.0034 \mathrm{~nm}$ for nine narrow spectral bands.

One of the key elements in the optical system of GOME is a quartz pre-disperser prism. The wavelength calibration is sensitive to the dispersion of this prism, whose refractive index varies with temperature. Thus, the calibration parameters from the lamp measurements are stored in the database as a function of this temperature. In the operational processing the most recent calibration parameters are then selected from the database according to the pre-disperser temperatures encountered in the actual orbit. Each individual GOME spectrum is, thus, implicitly corrected for temperature variations that are caused by seasonal variations, the position in the orbit, and the rate of degradation of thermally sensitive optical elements.

Figure 10 shows the time series of the pre-disperser temperature from 1995 to 2011 (blue dots). An increase of $\sim 4 \mathrm{~K}$ within the instrument's lifetime is found which is due to degradation of the thermal system. Furthermore, the curve exhibits a seasonal cycle with maximum values in December-January when the Sun-Earth distance is at a min-

imum. Outliers are caused by instrument and cooler switchoffs. Magenta dots denote the increase in the pre-disperser temperature along an orbit in Kelvin per hour $\left(\mathrm{K} \mathrm{h}^{-1}\right)$ for the years 1995 to 2003 . The increase along an orbit is due to warming of the satellite by the Sun and because light passes through the instrument. This analysis relies on the average of 60-70 days per year; for each day the temperature measured along the first orbit, which is always located between 120 and $160^{\circ} \mathrm{E}$, was investigated. The error bars are a measure of the intra-annual variability. We did not analyse the dependence of the pre-disperser temperature itself on longitude as in van Geffen (2004, his Fig. 3). They found a maximum of the predisperser temperature over the Atlantic and a minimum over the Pacific. Furthermore, they stated that the temperature increase along the orbits does not show a dependence on longitude. During the first 8 years of the mission the temperature rise along the illuminated part of one orbit increased from about $0.7 \mathrm{Kh}^{-1}$ to about $0.9 \mathrm{~K} \mathrm{~h}^{-1}$. Unfortunately, analysis of later years is not possible due to the ERS-2 tape recorder failure and incomplete orbits.

\subsection{Dark signal correction}

The detectors integrated in GOME are random access linear photo-diode arrays. One of the characteristics of these devices is a certain amount of dark current due to thermal leakage. It is expected that this current will depend on the orbital position of the satellite and also how much time has elapsed since the mission began. Therefore it is necessary to continuously monitor the dark current and the associated noise, which is done by means of periodically taken darkside measurements (Sect. 5.3.1). In this case the scan mirror points toward the GOME interior. The PMD detectors are 
non-integrating devices and, therefore, do not have a leakage current. Nevertheless, those detectors must be corrected for their zero offsets and the noise must be monitored (see Sect. 5.3.2).

\subsubsection{Dark current and dark current noise}

The complete dark signal comprises two parts: (i) a constant value of $\sim 140-150$ BU (binary units), which is called the fixed pattern readout noise (FPRN), and (ii) the timedependent leakage current itself, which is about $\sim 2 \mathrm{BU} \mathrm{s}^{-1}$. This value is quite small because of the low temperature $\left(-38^{\circ} \mathrm{C}\right)$ of the detector arrays. The dark signal measurements have to be taken with the same integration time patterns as those used for scanning and other calibration measurements, since it was found that a certain amount of crosstalk is present that depends on the integration time. However, the detector temperature is not taken into account for GOME as it is in the case for the dark signal correction of the GOME-2 instrument (Munro et al., 2016).

The dark signal correction is the subtraction of a mean dark signal spectrum from the measured signal $S_{i}^{\text {meas, } k}$ :

$S_{i}=S_{i}^{\text {meas }, k}-\overline{S_{i}^{\text {dark }, k}}$,

where $i=1, \ldots, 1024$ detector pixels. The integration time pattern $k$ describes the number of clock pulses, where one pulse takes $93.75 \mathrm{~ms}$, e.g., a time pattern of 640 is equivalent to $60 \mathrm{~s}$.

The mean dark signal for $n=10$ consecutive measurements is defined as

$\overline{S_{i}^{\mathrm{dark}, k}}=\frac{1}{n} \sum_{j=1}^{n}\left(S_{i}^{\mathrm{dark}, k}\right)_{j}$.

Figure 11 shows the dark signal as a function of time for the three most representative integration time patterns: (i) the normal scanning orbits with $12 \mathrm{~s}$ integration time for band $1 \mathrm{a}$ and $1.5 \mathrm{~s}$ for the other bands (with co-adding applied), (ii) the LED measurements for the pixel-to-pixel gain correction (see next Section) with $30 \mathrm{~s}$ integration time for all bands, and (iii) the polar view mode with $60 \mathrm{~s}$ integration time for band $1 \mathrm{a}$ and $6 \mathrm{~s}$ for the other bands. Figure 11 shows the dark signal for bands 1a, 2b, 3, and 4 (from top to bottom) and for time patterns (i) to (iii) from left to right. All panels denote a significant increase over time.

Note that the dark signal in bands $2 \mathrm{~b}, 3$, and 4 for the normal scanning orbits (Fig. 11, panels $\mathbf{a}, \mathbf{d}, \mathbf{g}$ and $\mathbf{j}$ ) is much higher due to the co-adding of four measurement sequences. At present there is no explanation for the behaviour of the signal from 2005 to 2007. It is most obvious in channel 4 for the normal scanning mode (panel $\mathbf{j}$ ) and for the polar view mode (panel l). The signal decreased significantly in 2005 (by $40 \mathrm{BU}$ for the normal scanning mode), reached a minimum in the beginning of 2006, and increased again, during which the entire development of this anomaly is quite smooth. The jumps in the time series (e.g., seen in channels 2 and 3 for the normal scanning mode and in channel 2 for the polar view mode) are due to instrument or cooler switchoffs or instrument anomalies.

The noted increase in the dark signal is an increase in the leakage current, i.e., the time-dependent part. Figure 12 shows the dark signal as a function of the integration time for four different years: 1997, 2002, 2007, and 2011. Different symbols and line styles denote the individual bands $1 \mathrm{a}$, $2 \mathrm{~b}, 3$, and 4 . The $y$ intercept represents the FPRN, which is about 140-150 BU and remains constant over the entire time period. The slope denotes the time-dependent leakage current, which is quite similar for all channels $\left(\sim 2 \mathrm{BU} \mathrm{s}^{-1}\right)$ and which increases over time. The increase is also almost identical for all channels and amounts to about $4 \mathrm{BU} \mathrm{s}^{-1}$ decade $^{-1}$ $\left(\sim 6.5 \mathrm{BU} \mathrm{s}^{-1}\right.$ from 1995 to 2011$)$. This is comparable to earlier work by Dehn (2003) and our previous study ColdeweyEgbers et al. (2008) as well as Munro et al. (2016), which analysed the dark signal for the GOME-2 instrument onboard the MetOp series of satellites using the same type of detectors. For OMI, which is a nadir-viewing UV-VIS imaging spectrograph using two-dimensional charge-coupled device (CCD) detectors (Levelt et al., 2006; Dobber et al., 2006), a 7 -fold dark current increase was found from 2005 to 2015 (Schenkeveld et al., 2017), and for GOMOS/ENVISAT (Global Ozone Monitoring by Occultation of Stars) using the same CCD detectors as OMI an even higher increase was found (Bertaux et al., 2010). Although the increase in the dark current seems to be significant, there is not necessarily a negative impact on the quality of the level 1 data products as long as appropriate dark current measurements are available and applied during the level 0-to-1 processing.

We found that it is not only the leakage current itself which changed over time, but also its distribution, which widened considerably. Figure 13 shows histograms of the dark signal for spectral band 1a (240-283 nm) for an integration time of $12 \mathrm{~s}$ (nominal scanning mode) for every 2 years from 1997 to 2011. The data correspond to Fig. 11a. Coloured numbers stuck to the individual histograms denote the median values and the FWHM of the distribution. The latter is additionally indicated by the filled rectangles. As seen in Fig. 11 the dark signal significantly increased over time from $\sim 176$ to $\sim 242$ BU. Furthermore a noticeable, almost 3-fold broadening of the distribution was found. FWHM increased from 2.7 to $7.4 \mathrm{BU}$. A widening of the dark current distribution was also noticed for OMI (Schenkeveld et al., 2017) and GOMOS (Bertaux et al., 2010).

The noise on the signals of the detector pixel readouts is expected to be constant over all detector pixels. For each detector pixel the standard deviation from all leakage measurements from one orbit with the same integration time is computed. The noise is then the average of all standard deviations. The annual mean noise level is shown in Fig. 14 (blue curves, left $y$ axis) as a function of time for three different integration time patterns (scanning, moon and LED). The error 

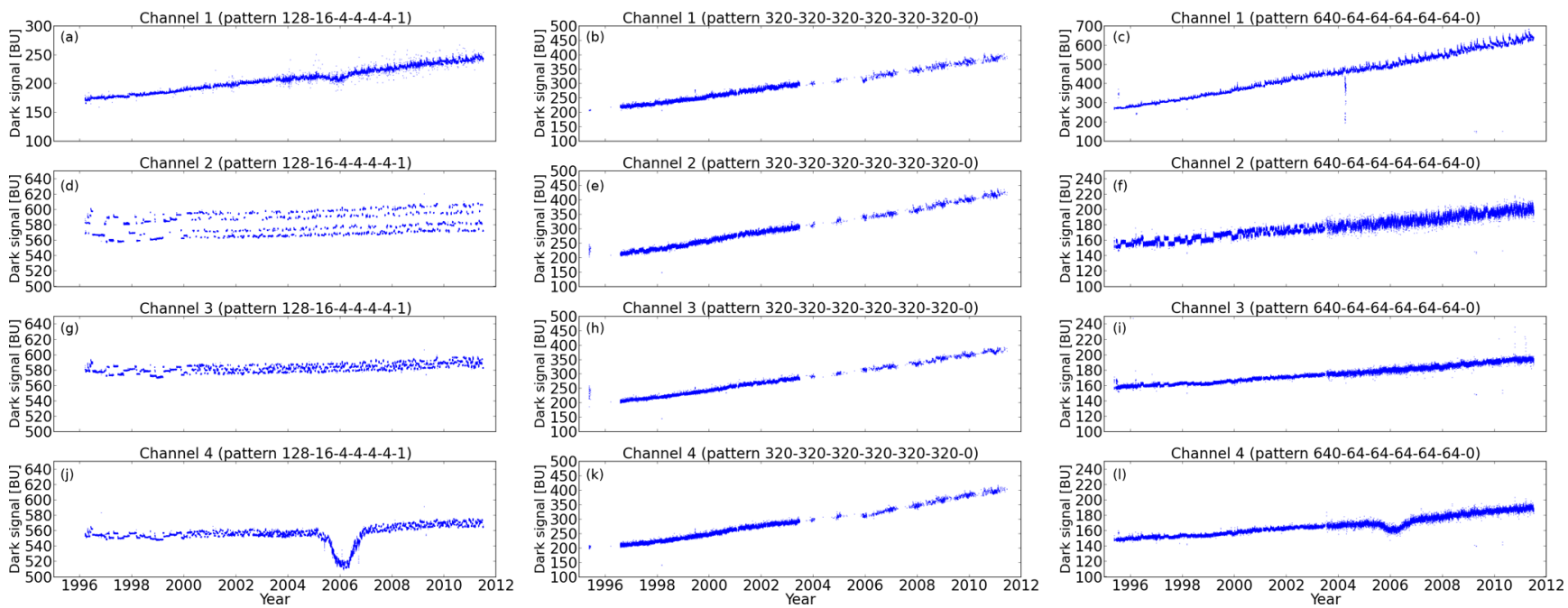

Figure 11. Dark signal in binary units (BU) as a function of time from 1995 to 2011 for three integration time patterns: normal scanning mode (12 s integration time for band 1a and $1.5 \mathrm{~s}$ for the other bands, co-adding applied for bands $2 \mathrm{a}, 2 \mathrm{~b}, 3$, and 4, a, d, g, j), LED measurement mode ( $30 \mathrm{~s}$ integration time for each band, $\mathbf{b}, \mathbf{e}, \mathbf{h}, \mathbf{k}$ ), and polar view mode $(60 \mathrm{~s}$ integration time for band $1 \mathrm{a}$ and $6 \mathrm{~s}$ for the other bands, $\mathbf{c}$, f, i, l). From top to bottom: band $1 \mathrm{a}$, band $2 \mathrm{~b}$, band 3 , and band 4 .

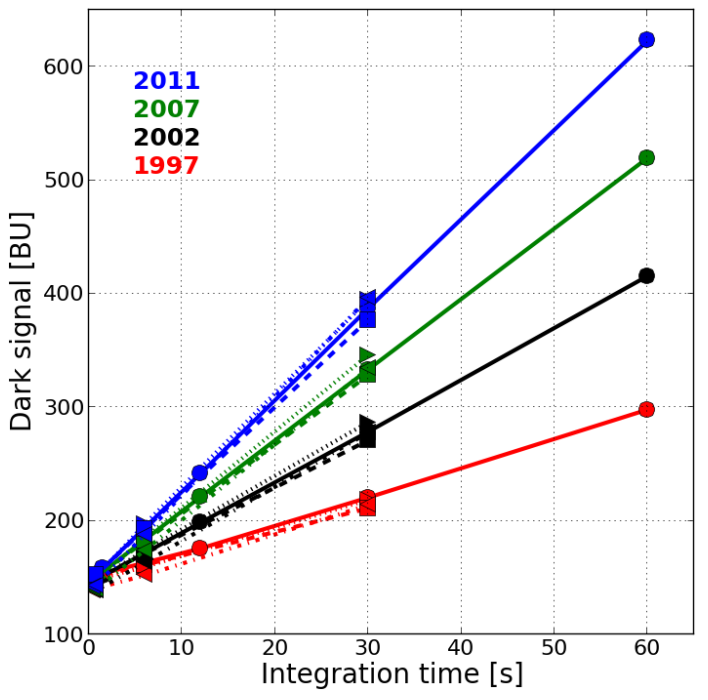

Figure 12. Dark signal in binary units (BU) as a function of integration time for January 1997 (red), 2002 (black), 2007 (green), and 2011 (blue), respectively. Different symbols and line styles denote channels 1a (solid), 2b (dotted), 3 (dashed), and 4 (dash-dotted).

bars denote the standard deviation for the annual mean. The lowest noise level $(\sim 2 \mathrm{BU})$ is found for LED dark signal calibration measurements that have the longest integration time (30 s), whereas the noise level for scanning and moon integration time pattern are quite similar and about $4 \mathrm{BU}$. The values remain more or less constant until June 2003. Afterward the noise level for LED dark signal calibration measurements slightly increased (dotted-dashed blue line), whereas a decrease is found for moon dark signal calibration

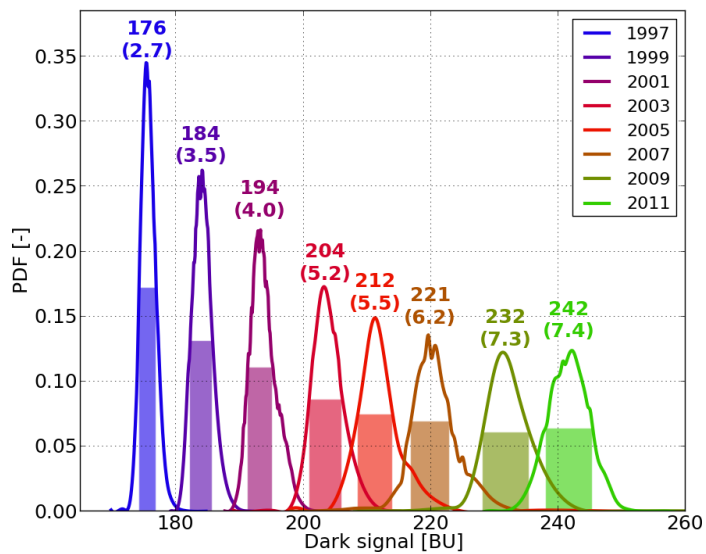

Figure 13. Probability density function (PDF) of the dark signal in spectral band $1 \mathrm{a}$ for an integration time of $12 \mathrm{~s}$ for every 2 years from 1997 to 2011. Coloured numbers denote the median value in binary units (BU) and the FWHM (in parenthesis) of the distribution. The latter is additionally indicated by the coloured rectangles.

measurements (dashed blue curve). Red curves (right $y$ axis) denote the number of available dark signal calibration measurements. The most significant decrease in the number of available measurements is for the LED dark signal calibration measurements (dotted-dashed red curve).

\subsubsection{PMD offset and noise}

The signals of the PMD detectors as non-integrating devices must be corrected for their zero offsets and the associated noise must be monitored. Figure 15 shows PMD offsets for each PMD as a function of time for the entire mission period. 


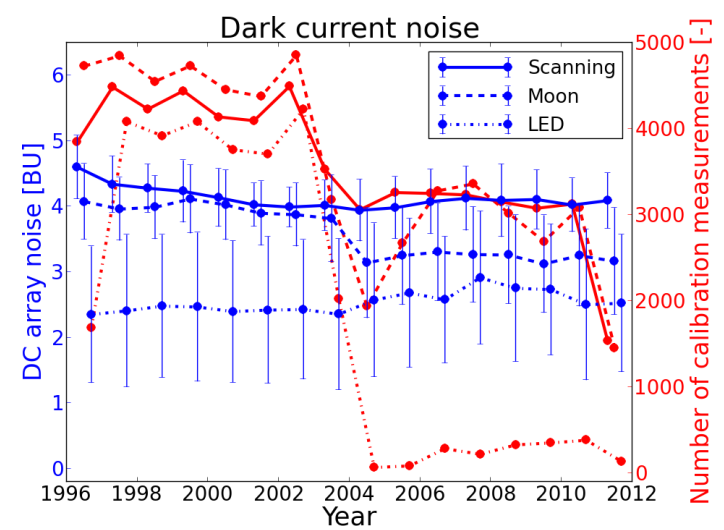

Figure 14. Annual mean dark current noise (blue curves, left $y$ axis) in binary units (BU) for three integration time patterns: scanning (solid curve), moon (dashed curve), and LED (dotted-dashed curve). Red curves (right $y$ axis) denote the number of available calibration measurements for the three individual time patterns.
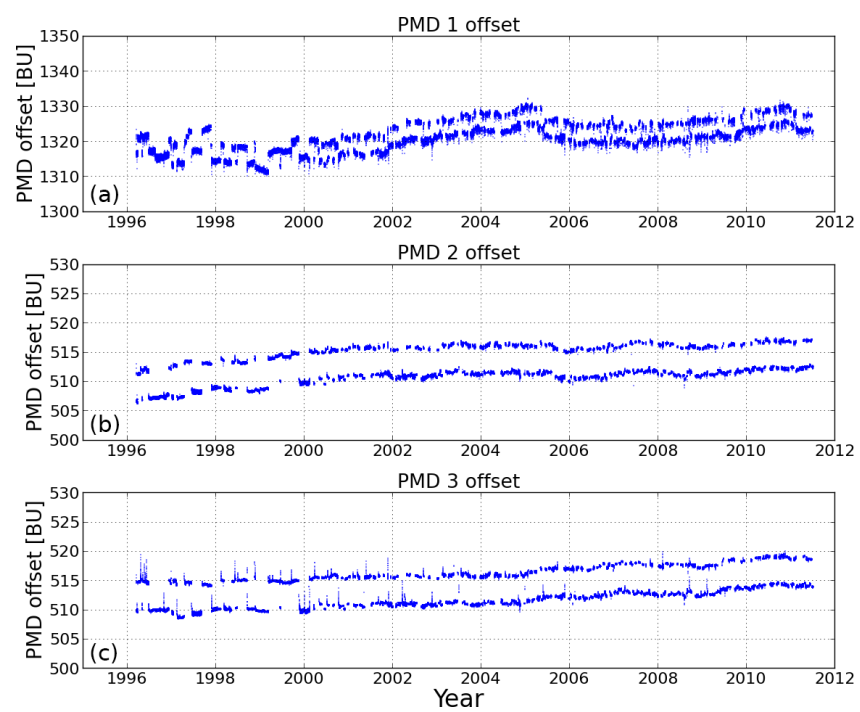

Figure 15. PMD offset in binary units (BU) as a function of time for PMD 1, 2, and 3 (a-c).

The offset of PMD 1 is about $1320 \mathrm{BU}$, whereas it is about $510 \mathrm{BU}$ for PMDs 2 and 3. All offsets indicate a very small increase of $0.8 \%$ in 16 years of the mission. The increase is nearly linear for PMDs 2 and 3, whereas for PMD 1 the increase started in 1999; the PMD 1 offset reached a maximum at the end of 2004, decreased in 2005 and increased again thereafter. For all PMDs the offsets seem to have two states, and jumps between the two states are due to cooler and instrument switch-offs as well as instrument anomalies.

Figure 16 shows the annual mean PMD noise as a function of time. The PMD noise is defined as the mean value of the standard deviations which are calculated for each PMD over all 16 individual PMD measurements. It is about 0.51.5 BU. The previous study (Coldewey-Egbers et al., 2008,

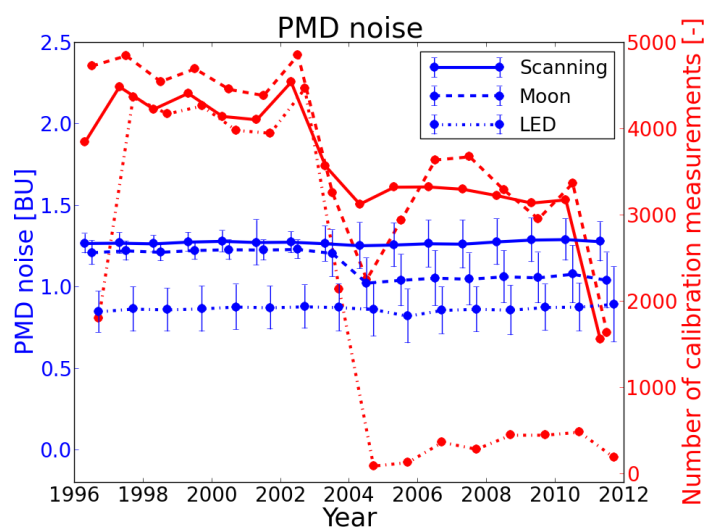

Figure 16. Annual mean PMD noise (blue curves, left $y$ axis) in binary units (BU) for three integration time patterns: scanning (solid curve), moon (dashed curve), and LED (dotted-dashed curve). Red curves (right $y$ axis) denote the number of available calibration measurements for the three individual time patterns.

their Fig. 9d) has shown the impact of the South Atlantic Anomaly (SAA) on the noise level, which increases significantly when measurements from this area are taken into account. In the new GDP-L1 version these calibration measurements are discarded (see following section). In general the noise level remains stable over the entire period although as a consequence of the tape recorder failure in June 2003 a slight change in the noise level was found, in particular for the moon dark signal calibration measurements.

\subsubsection{Impact of the South Atlantic Anomaly}

The South Atlantic Anomaly is an area of enhanced flux of energetic particles due to a dip in the Earth's inner Van Allen radiation belt. In this region low Earth orbit spacecrafts are exposed to higher-than-normal radiation levels and may suffer from damage (Heirtzler, 2002; Casadio and Arino, 2011). High energy protons impact the detectors of GOME, i.e., the background signal is higher than the normal dark signal, the noise is enhanced, and the measured spectra are also prone to intensity spikes caused by cosmic particles.

For this reason all calibration measurements in the SAA are discarded. The algorithm to identify the SAA uses the signal from PMD 1, since we found that the noise level on PMD 1 is a reliable indicator of the enhanced particle bombardment in the SAA region. Figure 17 shows a map of the GOME long-term mean PMD 1 noise derived from the first 5 years of the mission. The impact of the SAA clearly appears in terms of significantly enhanced PMD 1 noise in an oval-shaped region centred at the east coast of Brazil. The SAA spans from 50 to $0^{\circ} \mathrm{S}$ in latitude and from $90^{\circ} \mathrm{W}$ to $30^{\circ} \mathrm{E}$ in longitude. During the level 0-to-1 processing PMD measurements are grouped and for each group a noise value with respect to the median value is calculated. If the noise value exceeds a certain threshold all calibration measure- 


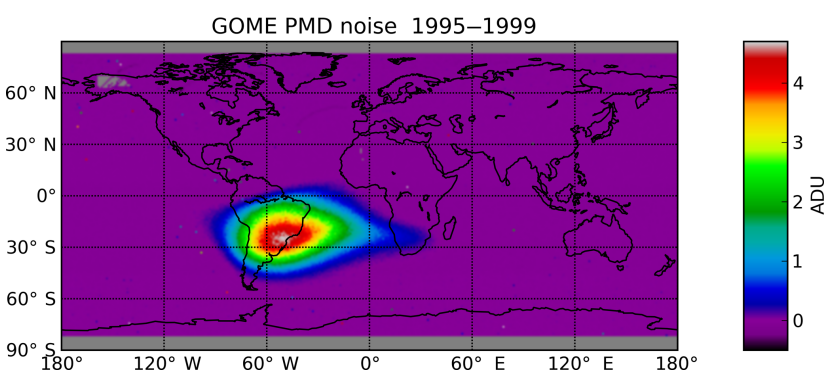

Figure 17. Map of the GOME long-term mean PMD 1 noise in $\mathrm{A} / \mathrm{D}$ (-converter) units (= binary units) derived from the first 5 years of the mission. Enhanced noise levels indicate measurements affected by the South Atlantic Anomaly.

ments from the group are discarded. This also includes the lamp measurements for the spectral calibration and the LED measurements for the pixel-to-pixel gain correction (see next Section). The new algorithm defines an "inside SAA" and an "outside SAA" region for dark signal values in the calibration database.

\subsection{Pixel-to-pixel gain correction}

The pixel-to-pixel gain in quantum efficiency of each diode detector array is characterised and corrected using internal LEDs. Each channel has a monochromatic red LED located between the channel optics and the detector window (see Fig. 1), i.e., the detectors are illuminated directly without any dispersing element in between that may suffer from degradation effects. The monitored detector signal corresponds to a superposition of a smoothly varying signal caused by the LED characteristics and a small-scale structure due to the slightly different sensitivity of each pixel. The determination of the correction spectra for each of the four channels is based on a mean value of several consecutive LED measurements and a smoothed curve through this average using a triangle filtering window:

$c_{i}=\frac{S_{i}^{\text {smooth }}}{\overline{S_{i}^{\mathrm{LED}}}}$,

where $c_{i}$ is the correction factor of detector pixel $i, \overline{S_{i}^{\mathrm{LED}}}$ is the mean value of several consecutive LED measurements, and $S_{i}^{\text {smooth }}$ is the smoothed curve through this averaged measurements. The latter is calculated by means of

$S_{i}^{\text {smooth }}=\frac{\sum_{k=-n}^{n} \frac{n-|k|}{n} \times \overline{S_{i+k}^{\mathrm{LED}}}}{\sum_{k=-n}^{n} \frac{n-|k|}{n}}$

using a triangle filtering window of width $n=5$. The application of the PPG correction is then simply

$S_{i}^{\mathrm{corr}}=S_{i} c_{i}$,

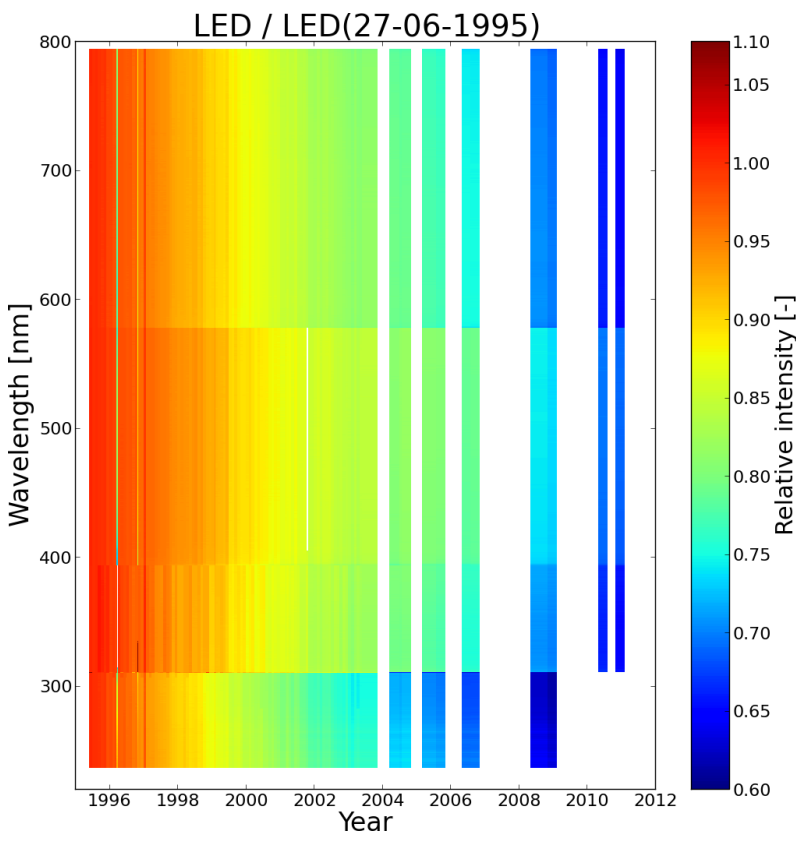

Figure 18. Relative intensity of LED spectra as a function of time ( $x$ axis) and wavelength ( $y$ axis) with respect to a reference spectrum from 27 June 1995.

where $S_{i}$ is the measured signal value of detector pixel $i$, and $S_{i}^{\text {corr }}$ is the corrected value.

Typically, the LED spectra were obtained in monthly intervals until 2003. From 2003 onward LED measurements are limited to two or three sequences per year. The absolute radiance correction due to the pixel-to-pixel variability is very small $(\sim 0.02 \%)$. However, it may not be negligible in wavelength regions used for the retrieval of weak absorbers such as bromine oxide. Figure 18 shows the relative intensity of the LED spectra as a function of time and wavelength with respect to a reference spectrum from the beginning of the measurements (27 June 1995). The nearly linear decrease, which was already detected in the previous study (ColdeweyEgbers et al., 2008), continued until the end of the mission in 2011 and is due to the degradation of the LEDs' brightnesses themselves. The output decreased to $\sim 60 \%$. It is almost homogeneous over the complete wavelength range of each channel. The steepest decrease is found in channel 1.

In addition we analysed the distribution of the PPG correction factors as a function of time. Figure 19 shows boxwhisker plots of the distribution for each channel and as a function of time. We show one distribution per year. In channel 1 the amplitude of the PPG correction spectrum is slightly larger than for the other channels. Nevertheless, the distribution of the correction spectrum remains roughly stable over the entire period, whereas for channel 2 a significant broadening of the distribution is found. The standard deviation increased by a factor of $\sim 2.5$ in this channel, which indicates that the variability in sensitivity between the individual de- 

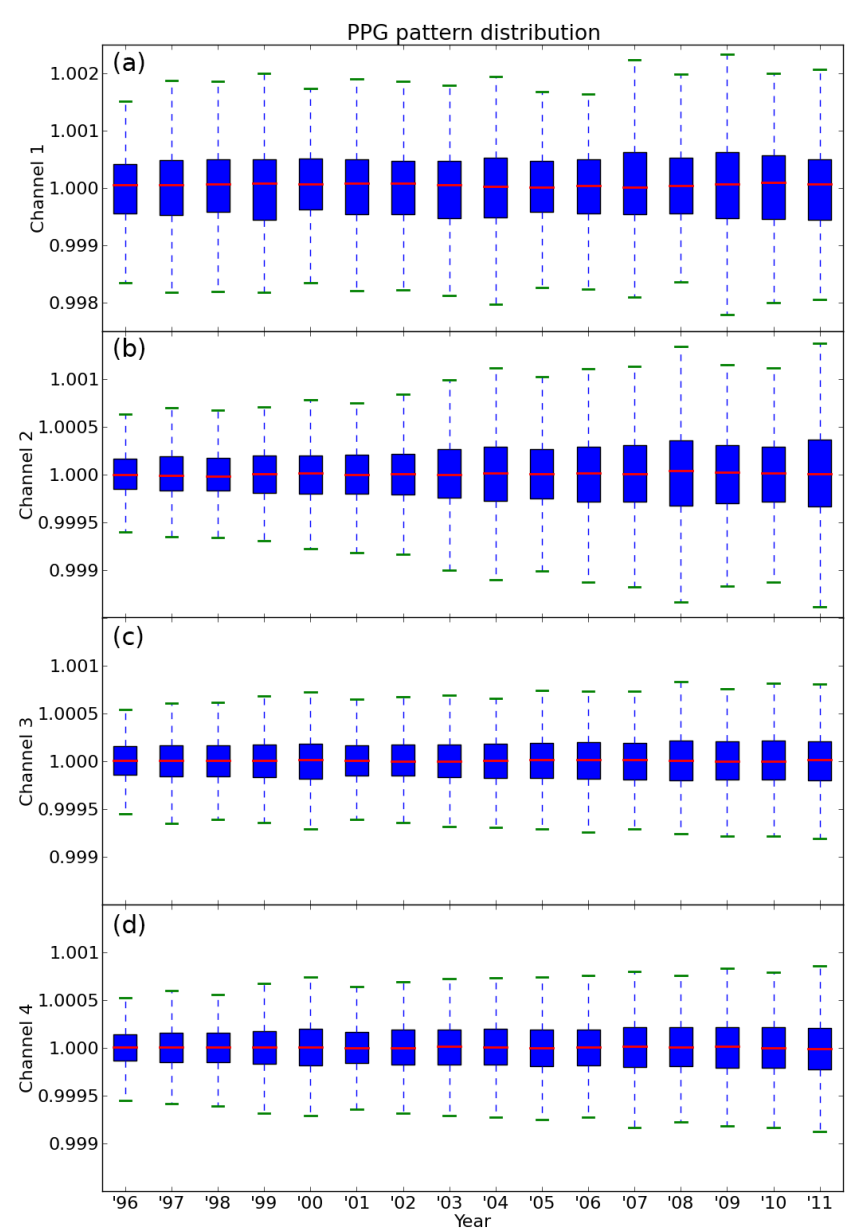

Figure 19. Box-whisker plots of the distribution of the PPG correction pattern as a function of time (one selected distribution per year) for channels 1, 2, 3, and 4 (a-d). Note the slightly different $y$ axis range for channel 1 . Red horizontal lines denote the median, the blue boxes denote the lower $(25 \%)$ and the upper $(75 \%)$ quartile, and the green caps denote the minimum and maximum values (except the outliers).

tector pixels increased significantly. For channels 3 and 4 a broadening of the distribution of $\sim 40 \%$ was found. For all channels we noticed that the number of outliers did not increase over the years (not shown in this plot), which indicates that the detector as a whole is affected and that the increase is not just due to a few strongly battered pixels.

\section{Summary and conclusions}

The Global Ozone Monitoring Experiment, launched in April 1995 on-board the second European Remote Sensing satellite, provided measurements of atmospheric trace constituents such as $\mathrm{O}_{3}, \mathrm{NO}_{2}, \mathrm{SO}_{2}, \mathrm{HCHO}, \mathrm{BrO}$, and $\mathrm{H}_{2} \mathrm{O}$ as well as aerosol and cloud parameters on a global scale for more than 16 years, before it was decommissioned in July
2011. The existing data archive of GOME can be considered as the European reference for follow-up atmospheric composition sensors like SCIAMACHY, OMI, GOME-2, and the Copernicus Sentinel missions S5P/S4/S5. Therefore, preservation as well as further improvement and exploitation of this unique data set are highly recommended.

Within the framework of the ESA's GOME-Evolution project a homogenised level 1 data product for the complete mission was generated for the first time, based on the new GDP-L1 Version 5.1, which contains fully calibrated radiances, irradiances, geolocation information, and selected calibration parameters. In addition, cloud parameters retrieved with the well-established OCRA and ROCINN algorithms have been integrated in the new product. The format and structure of the GOME L1 NetCDF-4 files are similar to other state-of-the-art EO products like S5P.

Furthermore, a detailed investigation of the long-term performance of the GOME instrument in terms of monitoring the various in-flight calibration parameters was carried out. This should ensure the high quality of the GOME (ir)radiance measurements that is needed to retrieve atmospheric geophysical products with highest accuracy.

The polarisation correction algorithm was improved in the new GDP-L1 5.1. Instead of climatological values the ozone columns derived from the GOME measurements themselves are used for the parameterisation of the generalised distribution function. By means of the daily solar irradiance measurements the degradation was monitored and corrected. Degradation can be explained in terms of deposits on the GOME scan mirror. Below $300 \mathrm{~nm}$ intensity decreased by $80 \%-95 \%$, which implies a significant deterioration of the signal-to-noise ratio and which may have a severe impact on the challenging retrieval of atmospheric parameters such as ozone profiles. The decrease in channel 2 is $40 \%-80 \%$. In channel 3 the decrease (10\%-40\%) started in 2001, whereas throughput changes in channel 4 are relatively small. Since 2001 the measurements were additionally affected by an ERS-2 pointing problem. A degradation correction algorithm has been developed and further improved which relies on the intensity measured in the early part of the mission and which comprises a wavelength- and a time-dependent part. In GDPL1 this correction is routinely applied to irradiance and radiance measurements. The degradation in reflectance, i.e., the differential degradation between solar irradiance and Earth radiance measurements has been monitored for two wavelengths, 325 and $335 \mathrm{~nm}$ (lower and upper limits of the total ozone fitting window), using cloud-free pixels over the $\mathrm{Sa}$ haran desert. Changes are of the order of $-10 \%$ to $30 \%$ and depend on wavelength and the viewing angle. Since changes in reflectance may result from both changes in instrument performance or changes in atmospheric conditions, no routine corrections are applied in GDP-L1.

For the spectral calibration special attention was paid to the identification of lamp lines that remain stable (with respect to the statistical moments) over the whole mission. This 
has resulted in an updated spectral line list used in GDP-L1 that improved the temporal stability of the wavelength assignment for the complete mission. For the leakage current an increase of $4 \mathrm{BU} \mathrm{s}^{-1}$ decade $^{-1}$ and a widening of the distribution were found. Typically, in GDP-L1 dark signal measurements from the same or a very close-by orbit are applied so that these changes do not have a negative impact on the measurement quality. The existing dark signal correction has been further improved by differentiating between measurements from outside and inside the SAA. Thereby, the enhanced background signal and noise level, which are typical for measurements from inside the SAA, are better accounted for. The output of the LEDs that are used to monitor the pixel-to-pixel sensitivity decreased to about $60 \%$ of the early-mission values. For channel 2 a significant broadening of the PPG distribution was observed.
Data availability. The new GOME L1 product access is immediately available after ESA Fast Registration at https://earth.esa.int/web/guest/data-access/ browse-data-products?p_p_id=datasetlist_WAR_

ospportlet\&instruments=GOME or https://earth.esa.int/web/guest/ -/gome-level-1-calibrated-and-geolocated-spectraproduct-1483 (last access: 9 September 2018). Processed by DLR on behalf of ESA, ERS-2 GOME Level 1 v5.1 data set. 
Appendix A: NetCDF structure of the new GOME level 1 products

The GOME level 1 product filename is constructed as follows. $<$ MMM $>_{-}<$CCCC $>_{-}<$TTTTTTTTTT $>_{-}<$instance ID $>$ .nc, where $<\mathrm{MMM}>$ is the mission ID, $<\mathrm{CCCC}>$ is the file class, and $<$ TTTTTTTTTT $>(=<$ FFFF $><$ DDDDDD $>)$ is a mission-specific file type. $<\mathrm{FFFF}>$ is the file category and $<$ DDDDDD $>$ is a product semantic descriptor. $<$ instance ID $>$ consists of start time, end time, orbit number, packet version, processor version, and processing time. The packet version is a version number that is specific for the combination of processor version, input data (for example calibration data) version, and configuration version. For GOME Level 1 products, the mission ID is ER2 for ERS2. The file class can be TEST or RPRO for test data or reprocessing. The file type field contains an instrument identifier (GOM) as file category and the processing level (L1B or $\mathrm{L} 2$ _ or L0__) as semantic descriptor. The packet version is 2 and the processor version is currently 5.1. We encode these versions into "02_051000" as the versions part of the "instance ID". The file extension is ".nc" that is typically used for netCDF files. All time strings in the filename and product are formatted in ISO 6801 format. Following this scheme, the result would be as follows, for example: ER2_TEST_GOM_L1B__20010811T032404_20010811 T050712_32981_02_051000_20150311T151024.nc. Product size may vary between 60 and $75 \mathrm{MB}$. Products which are measured after the ERS-2 tape recorder problem in June 2003 are typically smaller because they do not comprise measurements for the entire orbit.

The different dimensions in the GOME level 1 netCDF file are time $(=1)$, which corresponds to one time per orbit; scanline $(\approx 500)$, which corresponds to one complete scan comprising three forward and one backward scan; ground_pixel (3 or 1), which corresponds to the number of across-track scans; detector channel $(=4)$, which corresponds to the number of detectors; band $(=6)$, which corresponds to the number of spectral windows; and spectral_channel, which corresponds to the total number of detector pixels.

Figure A1 provides an overview of the netCDF structure of the level 1 file. In addition to metadata and instrument-related parameters, calibration data and irradiance measurements are available. The radiance measurements themselves are organised in groups for different modes: nadir, static_view, narrow_swath, north- and southpolar_view, sun, or moon. Forward and backward scans are separated into different groups. Inside these groups there are subgroups for bands and PMDs. A band is a part of a channel which can have its own integration time and co-adding factor. Integration times may change during one orbit. All subgroups contain several variables and attributes. For a detailed description and the complete list of all variables we refer to Aberle (2018).

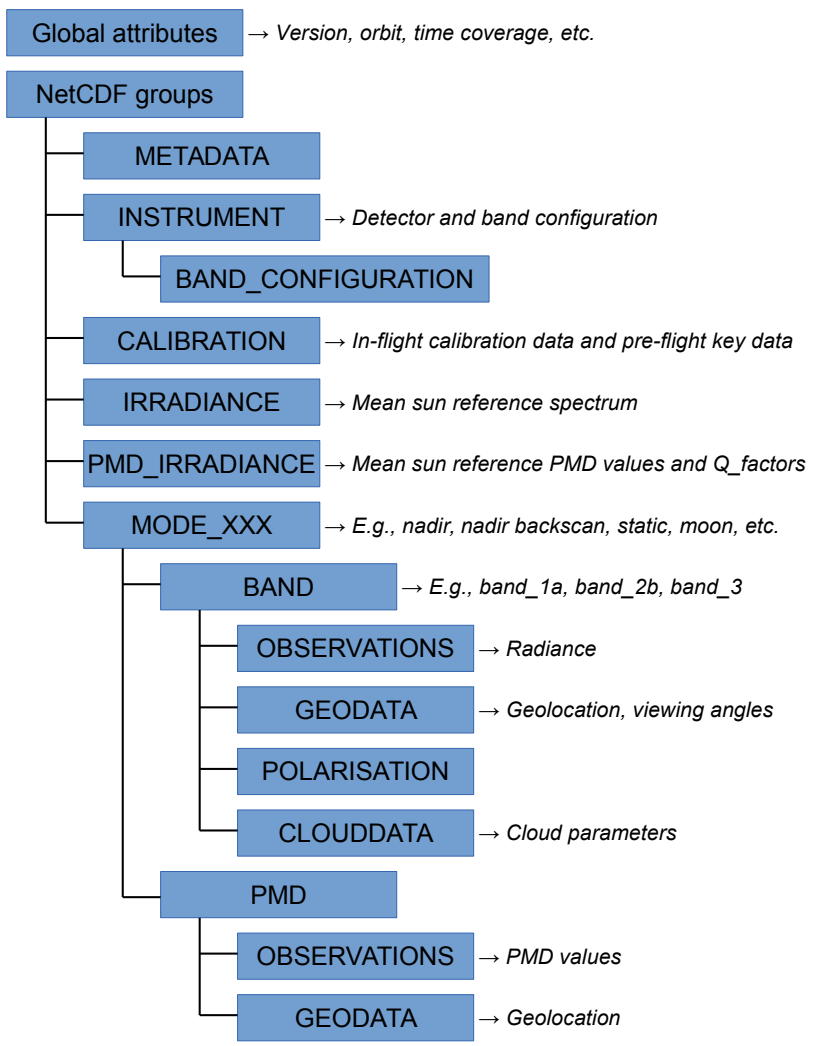

Figure A1. NetCDF structure of new GOME level 1 file generated with GDP-L1 version 5.1. Measurements are organised in groups for different modes and bands (see text for more explanations). 
Author contributions. MCE performed the analysis of the in-flight calibration parameters and the instrument degradation, and wrote the paper. SS developed the new polarisation correction algorithm and wrote the description of the calibration algorithms. BA was responsible for updating the GDPL1 processor, including the development of the new GOME L1 product format, and for reprocessing the complete GOME data set. DL led the GOME-Evolution project, contributed to the text and reviewed the manuscript. AD was the technical officer of the GOME-Evolution project.

Competing interests. The authors declare that they have no conflict of interest.

Acknowledgements. This work was performed in the framework of the ESA GOME-Evolution project. Particular thanks to Wolfgang Lengert, ERS-2 Mission Manager, for making this work possible. Thanks to Kai-Uwe Eichmann (IUP-B), Andreas Richter (IUP-B), Mark Weber (IUP-B), Steffen Beirle (MPIC), and Gabriele Brizzi (SERCO) for helpful feedback on the prototype version of the new GOME L1 product.

The article processing charges for this open-access

publication were covered by a Research

Centre of the Helmholtz Association.

Edited by: Folkert Boersma

Reviewed by: two anonymous referees

\section{References}

Aben, I., Eisinger, M., Hegels, E., and Tanzi, C.: GDAQI Final Report, Tech. rep., ESA/ESRIN, Frascati, Italy, TNGDAQI-003 SR/2000, available at: http://wdc.dlr.de/sensors/ gome/degradation_files/degradation.php (last access: 26 July 2018), 2000.

Aberle, B.: GOME ERS-2 Level 1 Product User Manual, Tech. rep., German Aerospace Centre (DLR), Oberpfaffenhofen, Germany, ER-PS-DLR-GO-0016, Issue 6/D, available at: https://earth.esa. int/documents/700255/3497594/GOME-DLR-L1-PUM_6D. pdf/f33fee60-20a8-4065-859f-e79a5b1b740b, last access: 26 July 2018.

ATMOS: ATMOS 2012 Conference - Advances in Atmospheric Science and Applications: Session Summaries and Recommendations, EOEP-DTEX-EOPS-RD-12-0002, available at: http://old.esaconferencebureau.com/docs/default-source/atmos_ docs $2 /$ recommendations-summaries.pdf (last access: 26 July 2018), 2012.

Balis, D., Lambert, J.-C., van Roozendael, M., Spurr, R., Loyola, D., Livschitz, Y., Valks, P., Amiridis, V., Gerard, P., Granville, J., and Zehner, C.: Ten years of GOME/ERS2 total ozone data - The new GOME data processor (GDP) version 4: 2. Ground-based validation and comparisons with TOMS V7/V8, J. Geophys. Res., 112, D07307, https://doi.org/10.1029/2005JD006376, 2007.

Beirle, S., Lampel, J., Wang, Y., Mies, K., Dörner, S., Grossi, M., Loyola, D., Dehn, A., Danielczok, A., Schröder, M., and Wag- ner, T.: The ESA GOME-Evolution "Climate" water vapor product: a homogenized time series of $\mathrm{H}_{2} \mathrm{O}$ columns from GOME, SCIAMACHY, and GOME-2, Earth Syst. Sci. Data, 10, 449468, https://doi.org/10.5194/essd-10-449-2018, 2018.

Bertaux, J. L., Kyrölä, E., Fussen, D., Hauchecorne, A., Dalaudier, F., Sofieva, V., Tamminen, J., Vanhellemont, F., Fanton d'Andon, O., Barrot, G., Mangin, A., Blanot, L., Lebrun, J. C., Pérot, K., Fehr, T., Saavedra, L., Leppelmeier, G. W., and Fraisse, R.: Global ozone monitoring by occultation of stars: an overview of GOMOS measurements on ENVISAT, Atmos. Chem. Phys., 10, 12091-12148, https://doi.org/10.5194/acp-10-12091-2010, 2010.

Bovensmann, H., Burrows, J. P., Buchwitz, M., Frerick, J., Noël, S., Rozanov, V. V., Chance, K. V., and Goede, A. P. H.: SCIAMACHY: Mission Objectives and Measurement Modes, J. Atmos. Sci., 56, 127-150, https://doi.org/10.1175/15200469(1999)056<0127:SMOAMM>2.0.CO;2, 1999.

Bramstedt, K., Noël, S., Bovensmann, H., Burrows, J. P., Lerot, C., Tilstra, L., Lichtenberg, G., Dehn, A., and Fehr, T.: SCIAMACHY Monitoring Factors: Observation and End-to-End Correction of Instrument Performance Degradation, in: Proceedings of the ESA Atmospheric Science Conference, 7-11 September 2009, Barcelona, Spain, ESA Special Publication 676, 2009.

Burrows, J. P., Weber, M., Buchwitz, M., Rozanov, V. V., Ladstädter-Weissenmayer, A., Richter, A., de Beek, R., Hoogen, R., Bramstedt, K., Eichmann, K.-U., Eisinger, M., and Perner, D.: The Global Ozone Monitoring Experiment (GOME): Mission Concept and First Scientific Results, J. Atmos. Sci., 56, 151-175, https://doi.org/10.1175/15200469(1999)056<0151:TGOMEG>2.0.CO;2, 1999.

Cai, Z., Liu, Y., Liu, X., Chance, K., Nowlan, C., Lang, R., Munro, R., and Suleiman, R.: Characterization and correction of Global Ozone Monitoring Experiment 2 ultraviolet measurements and application to ozone profile retrievals, J. Geophys. Res., 117, D07305, https://doi.org/10.1029/2011JD017096, 2012.

Casadio, S. and Arino, O.: Monitoring the South Atlantic Anomaly using ATSR instrument series, Adv. Space Res., 48, 1056-1066, https://doi.org/10.1016/j.asr.2011.05.014, 2011.

Coldewey-Egbers, M., Slijkhuis, S., Aberle, B., and Loyola, D.: Long-term analysis of GOME in-flight calibration parameters and instrument degradation, Appl. Opt., 47, 4749-4761, https://doi.org/10.1364/AO.47.004749, 2008.

Coldewey-Egbers, M., Loyola, D. G., Koukouli, M., Balis, D., Lambert, J.-C., Verhoelst, T., Granville, J., van Roozendael, M., Lerot, C., Spurr, R., Frith, S. M., and Zehner, C.: The GOMEtype Total Ozone Essential Climate Variable (GTO-ECV) data record from the ESA Climate Change Initiative, Atmos. Meas. Tech., 8, 3923-3940, https://doi.org/10.5194/amt-8-3923-2015, 2015.

Dehn, A.: Long Term Monitoring of GOME Diffuser Reflectivity and Dark Signal Analysis, Tech. rep., ESA-ESRIN, ERSESPPA-EOPG-TN-03-0010, Issue 1.0, available at: https://earth. esa.int/documents/10174/1596664/Gome28.pdf (last access: 26 July 2018), 2003.

De Smedt, I., Müller, J.-F., Stavrakou, T., van der A, R., Eskes, H., and Van Roozendael, M.: Twelve years of global observations of formaldehyde in the troposphere using GOME and SCIAMACHY sensors, Atmos. Chem. Phys., 8, 4947-4963, https://doi.org/10.5194/acp-8-4947-2008, 2008. 
DLR on behalf of ESA: ERS-2 GOME Level 1 v5.1, available at: https://earth.esa.int/web/guest/-/ gome-level-1-calibrated-and-geolocated-spectraproduct-1483, last access: 9 September 2018.

Dobber, M. R.: GOME moon measurements, including instrument characterisation and moon albedo, in: 3rd ERS Scientific Symposium, Florence, Italy, ESA SP-414 Vol.II, p. 743, 1997.

Dobber, M. R., Goede, A. P. H., and Burrows, J. P.: Observations of the moon by the global ozone monitoring experiment: radiometric calibration and lunar albedo, Appl. Opt., 37, 7832-7841, https://doi.org/10.1364/AO.37.007832, 1998.

Dobber, M. R., Dirksen, R. J., Levelt, P. F., van den Oord, G. H. J., Voors, R. H. M., Kleipool, Q., Jaross, G., Kowalewski, M., Hilsenrath, E., Leppelmeier, G. W., de Vries, J., Dierssen, W., and Rozemeijer, N. C.: Ozone Monitoring Instrument Calibration, IEEE T. Geosci. Remote, 44, 1209-1238, https://doi.org/10.1109/TGRS.2006.869987, 2006.

ESA: GOME Mission Operations Overview, available at: https://earth.esa.int/web/sppa/mission-performance/ esa-missions/ers-2/gome/mission-operations-overview, last access: 26 July 2018.

Garane, K., Lerot, C., Coldewey-Egbers, M., Verhoelst, T., Koukouli, M. E., Zyrichidou, I., Balis, D. S., Danckaert, T., Goutail, F., Granville, J., Hubert, D., Keppens, A., Lambert, J.-C., Loyola, D., Pommereau, J.-P., Van Roozendael, M., and Zehner, C.: Quality assessment of the Ozone_cci Climate Research Data Package (release 2017) - Part 1: Ground-based validation of total ozone column data products, Atmos. Meas. Tech., 11, 13851402, https://doi.org/10.5194/amt-11-1385-2018, 2018.

GCOS: Systematic Observation Requirements for Satellite-Based Data Products for Climate - 2011 Update, availabele at: http: //www.wmo.int/pages/prog/gcos/Publications/gcos-154.pdf (last access: 26 July 2018), 2011.

GOME Users Manual: Tech. rep., ESA/ESTEC, Noordwijk, The Netherlands, ESA SP-1182, available at: https://earth.esa.int/ documents/10174/1596664/GOME05.pdf (last access: 26 July 2018), 1995.

Hegels, E., Aben, I., Slijkhuis, S., and Tanzi, C. P.: GOME Degradation Correction at Solar Activity Maximum, in: Proceedings of the ERS-ENVISAT Symposium, ESA Special Publication 461, CD-ROM, ISBN 92-9092-685-6, ESA Publications Division, Noordwijk, Holland, 2001.

Heirtzler, J. R.: The future of the South Atlantic anomaly and implications for radiation damage in space, J. Atmos. Sol.-Terr. Phy., 64, 1701-1708, https://doi.org/10.1016/S1364-6826(02)001207, 2002.

Helder, D. L., Basnet, B., and Morstad, D. L.: Optimized identification of worldwide radiometric pseudo-invariant calibration sites, Can. J. Remote Sens., 36, 527-539, https://doi.org/10.5589/m10085, 2010.

Heue, K.-P., Coldewey-Egbers, M., Delcloo, A., Lerot, C., Loyola, D., Valks, P., and van Roozendael, M.: Trends of tropical tropospheric ozone from 20 years of European satellite measurements and perspectives for the Sentinel-5 Precursor, Atmos. Meas. Tech., 9, 5037-5051, https://doi.org/10.5194/amt-9-50372016, 2016.

Lerot, C., van Roozendael, M., Spurr, R., Loyola, D., ColdeweyEgbers, M., Kochenova, S., van Gent, J., Koukouli, M., Balis, D., Lambert, J.-C., Granville, J., and Zehner, C.: Homogenized total ozone data records from the European sensors GOME/ERS2, SCIAMACHY/Envisat, and GOME-2/MetOp-A, J. Geophys. Res., 119, 1639-1662, https://doi.org/10.1002/2013JD020831, 2014.

Levelt, P., van den Oord, G., Dobber, M., Malkki, A., Visser, H., de Vries, J., Stammes, P., Lundell, J., and Saari, H.: The Ozone Monitoring Instrument, IEEE T. Geosci. Remote, 44, 10931101, https://doi.org/10.1109/TGRS.2006.872333, 2006.

Liu, X., Chance, K., and Kurosu, T. P.: Improved ozone profile retrievals from GOME data with degradation correction in reflectance, Atmos. Chem. Phys., 7, 1575-1583, https://doi.org/10.5194/acp-7-1575-2007, 2007.

Lorente, A., Boersma, K. F., Stammes, P., Tilstra, L. G., Richter, A., Yu, H., Kharbouche, S., and Muller, J.-P.: The importance of surface reflectance anisotropy for cloud and $\mathrm{NO}_{2}$ retrievals from GOME-2 and OMI, Atmos. Meas. Tech., 11, 4509-4529, https://doi.org/10.5194/amt-11-4509-2018, 2018.

Loyola, D. G., Balzer, W., Aberle, B., Bittner, M., Kretschel, K., Muehle, H., Ruppert, T., Schmid, C., Slijkhuis, S., Spurr, R., Thomas, W., Wieland, T., and Wolfmueller, M.: Ground Segment for ERS-2/GOME Sensor at the German D-PAF, in: 3rd ERS Scientific Symposium, Florence, Italy, ESA SP-414 Vol. II, 591-596, 1997.

Loyola, D. G., Thomas, W., Spurr, R., and Mayer, B.: Global patterns in daytime cloud properties derived from GOME backscatter UV-VIS measurements, Int. J. Remote Sens., 31, 4295-4318, https://doi.org/10.1080/01431160903246741, 2010.

Loyola, D. G., Koukouli, M. E., Valks, P., Balis, D. S., Hao, N., van Roozendael, M., Spurr, R. J. D., Zimmer, W., Kiemle, S., Lerot, C., and Lambert, J.-C.: The GOME-2 total column ozone product: Retrieval algorithm and ground-based validation, J. Geophys. Res., 116, D07302, https://doi.org/10.1029/2010JD014675, 2011.

Loyola, D. G., Gimeno García, S., Lutz, R., Argyrouli, A., Romahn, F., Spurr, R. J. D., Pedergnana, M., Doicu, A., Molina García, V., and Schüssler, O.: The operational cloud retrieval algorithms from TROPOMI on board Sentinel-5 Precursor, Atmos. Meas. Tech., 11, 409-427, https://doi.org/10.5194/amt-11-4092018, 2018.

Lutz, R., Loyola, D., Gimeno García, S., and Romahn, F.: OCRA radiometric cloud fractions for GOME-2 on MetOp-A/B, Atmos. Meas. Tech., 9, 2357-2379, https://doi.org/10.5194/amt-9-23572016, 2016.

Mishra, N., Helder, D., Angal, A., Choi, J., and Xiong, X.: Absolute Calibration of Optical Satellite Sensors Using Libya 4 Pseudo Invariant Calibration Site, Remote Sens., 6, 1327-1346, https://doi.org/10.3390/rs6021327, 2014.

Mount, G. H., Sanders, R. W., and Brault, J. W.: Interference effects in reticon photodiode array detectors, Appl. Opt., 31, 851-858, https://doi.org/10.1364/AO.31.000851, 1992.

Munro, R., Lang, R., Klaes, D., Poli, G., Retscher, C., Lindstrot, R., Huckle, R., Lacan, A., Grzegorski, M., Holdak, A., Kokhanovsky, A., Livschitz, J., and Eisinger, M.: The GOME2 instrument on the Metop series of satellites: instrument design, calibration, and level 1 data processing - an overview, Atmos. Meas. Tech., 9, 1279-1301, https://doi.org/10.5194/amt-9-12792016, 2016. 
Murray, J. E.: Atlas of the spectrum of a platinum/chromium/neon hollow-cathode reference lamp in the region $240-790 \mathrm{~nm}$, Final Report to ESA, John Wheaton Associates, 1994.

Noël, S., Bramstedt, K., Bovensmann, H., Burrows, J., Gottwald, M., and Krieg, E.: SCIAMACHY Degradation Monitoring Results, in: Proceedings of the ENVISAT Symposium, 23-27 April 2007, Montreux, Switzerland, ESA Special Publication 636, 2007.

Pan, C., Weng, F., Beck, T., Flynn, L., and Ding, S.: Recent Improvements to Suomi NPP Ozone Mapper Profiler Suite Nadir Mapper Sensor Data Records, IEEE T. Geosci. Remote, 55, 5770-5776, https://doi.org/10.1109/TGRS.2017.2714103, 2017.

Press, W. H., Teukolsky, S. A., and Vetterling, W. T.: Numerical Recipes in Fortran 77, Cambridge University Press, 1992.

Schenkeveld, V. M. E., Jaross, G., Marchenko, S., Haffner, D., Kleipool, Q. L., Rozemeijer, N. C., Veefkind, J. P., and Levelt, P. F.: In-flight performance of the Ozone Monitoring Instrument, Atmos. Meas. Tech., 10, 1957-1986, https://doi.org/10.5194/amt-10-1957-2017, 2017.

Schutgens, N. A. J. and Stammes, P.: Parametrisation of Earth's polarisation spectrum in the ultra-violet, J. Quant. Spectrosc. Ra., 75, 239-255, https://doi.org/10.1016/S0022-4073(01)00248-5, 2002.

Slijkhuis, S.: CHEOPS-GOME - Algorithm Theoretical Basis Document - Level 0 to 1 Processing Update, Tech. rep., German Aerospace Centre (DLR), Oberpfaffenhofen, Germany, CHTN-DLR-GO-0003, Issue 1/B, available at: https://wdc.dlr.de/ sensors/gome/degradation_files/literature/atbd_cheops.pdf (last access: 26 July 2018), 2006.

Slijkhuis, S. and Aberle, B.: GOME/ERS-2 Level 0 to $1 \mathrm{~b}$ ATBD, Tech. rep., German Aerospace Centre (DLR), Oberpfaffenhofen, Germany, GOME-DLR-L1-ATBD, Issue 7.0, available at: https://earth.esa.int/documents/ 700255/3497594/GOME-DLR-L1-ATBD_V7A.pdf/

c8c4a130-3fd9-4f98-b6d9-5859689f52ed (last access: 26 July 2018), 2016.

Slijkhuis, S., Aberle, B., and Loyola, D.: Improvements of GDP Level 0-1 processing system in the framework of CHEOPS-GOME, in: Proceedings of the Atmospheric Science Conference, edited by: ESA Spec. Publ. SP-628, available at: http://earth.esa.int/workshops/atmos2006/participants/ 516/paper_paper_ASW_cheops_final.pdf (last access: 26 July 2018), 2006.

Smith, D. L. and Cox, C. V.: (A)ATSR Solar Channel On-Orbit Radiometric Calibration, IEEE T. Geosci. Remote, 51, 1370-1382, https://doi.org/10.1109/TGRS.2012.2230333, 2013.

Snel, R.: In-orbit optical path degradation: GOME experience and SCIAMACHY prediction, in: Proceedings of the ERS-ENVISAT Symposium, edited by: ESA Spec. Publ. SP-461, CD-ROM, ISBN: 92-9092-685-6, 2001.

Sun, J., Xiong, X., Angal, A., Chen, H., Wu, A., and Geng, X.: Time-Dependent Response Versus Scan Angle for MODIS Reflective Solar Bands, IEEE T. Geosci. Remote, 52, 3159-3174, https://doi.org/10.1109/TGRS.2013.2271448, 2014.
Tanzi, C., Snel, R., Hasekamp, O., and Aben, I.: Degradation of UV Earth Albedo Observations by GOME, in: Proceedings of the ERS-ENVISAT Symposium, ESA Special Publication 461, CDROM, ISBN 92-9092-685-6, ESA Publications Division, Noordwijk, Holland, 2001.

Tilstra, L. G., de Graaf, M., Aben, I., and Stammes, P.: Inflight degradation correction of SCIAMACHY UV reflectances and Absorbing Aerosol Index, J. Geophys. Res., 117, D06209, https://doi.org/10.1029/2011JD016957, 2012.

Uprety, S. and Cao, C.: Suomi NPP VIIRS reflective solar band onorbit radiometric stability and accuracy assessment using desert and Antarctica Dome C sites, Remote Sens. Environ., 166, 106115, https://doi.org/10.1016/j.rse.2015.05.021, 2015.

USGS: CEOS Pseudo Invariant Calibration Sites, available at: https://calval.cr.usgs.gov/rst-resources/sites_catalog/ ceos-reference-sites/, last access: 26 July 2018.

van der A, R. J., van Oss, R. F., Piters, A. J. M., Fortuin, J. P. F., Meijer, Y. J., and Kelder, H. M.: Ozone profile retrieval from recalibrated Global Ozone Monitoring Experiment data, J. Geophys. Res., 107, ACH 2-1-ACH 2-10, https://doi.org/10.1029/2001JD000696, 2002.

van Geffen, J. H. G. M.: Wavelength calibration of spectra measured by the Global Ozone Monitoring Experiment: variations along orbits and in time, Appl. Opt., 43, 695-705, https://doi.org/10.1364/AO.43.000695, 2004.

van Geffen, J. H. G. M. and van Oss, R. F.: Wavelength calibration of spectra measured by the Global Ozone Monitoring Experiment by use of a high-resolution reference spectrum, Appl. Opt., 42, 2739-2753, https://doi.org/10.1364/AO.42.002739, 2003.

van Geffen, J. H. G. M., Boersma, K. F., Van Roozendael, M., Hendrick, F., Mahieu, E., De Smedt, I., Sneep, M., and Veefkind, J. P.: Improved spectral fitting of nitrogen dioxide from OMI in the 405-465 nm window, Atmos. Meas. Tech., 8, 1685-1699, https://doi.org/10.5194/amt-8-1685-2015, 2015.

van Peet, J. C. A., van der A, R. J., Tuinder, O. N. E., Wolfram, E., Salvador, J., Levelt, P. F., and Kelder, H. M.: Ozone ProfilE Retrieval Algorithm (OPERA) for nadir-looking satellite instruments in the U-VIS, Atmos. Meas. Tech., 7, 859-876, https://doi.org/10.5194/amt-7-859-2014, 2014.

van Roozendael, M., Spurr, R., Loyola, D., Lerot, C., Balis, D., Lambert, J.-C., Zimmer, W., van Gent, J., van Geffen, J., Koukouli, M., Granville, J., Doicu, A., Fayt, C., and Zehner, C.: Sixteen years of GOME/ERS-2 total ozone data: The new direct-fitting GOME Data Processor (GDP) version 5 - Algorithm description, J. Geophys. Res., 117, D03305, https://doi.org/10.1029/2011JD016471, 2012.

Voors, R., Dobber, M., Dirksen, R., and Levelt, P.: Method of calibration to correct for cloud-induced wavelength shifts in the Aura satellite's Ozone Monitoring Instrument, Appl. Opt., 45, 36523658, https://doi.org/10.1364/AO.45.003652, 2006.

Weber, M., Loyola, D., Richter, A., van Roozendael, M., and Wagner, T.: GOME Web Gallery, availabe at: https://earth.esa.int/ web/sppa/documentation/galleries/uvn/, last access: 13 September 2018 .

Zoogman, P., Liu, X., Chance, K., Sun, Q., Schaaf, C., Mahr, T., and Wagner, T.: A climatology of visible surface reflectance spectra, J. Quant. Spectrosc. Ra., 180, 39-46, https://doi.org/10.1016/j.jqsrt.2016.04.003, 2016. 